\title{
VEGF induces sensory and motor peripheral plasticity, alters bladder function, and promotes visceral sensitivity
}

\author{
Anna P Malykhina', Qi Lei ${ }^{1}$, Chris S Erickson², Miles L Epstein², Marcia R Saban³ ${ }^{3}$ Carole A Davis ${ }^{3}$ \\ and Ricardo Saban ${ }^{3^{*}}$
}

\begin{abstract}
Background: This work tests the hypothesis that bladder instillation with vascular endothelial growth factor (VEGF) modulates sensory and motor nerve plasticity, and, consequently, bladder function and visceral sensitivity. In addition to C57BL/6J, ChAT-cre mice were used for visualization of bladder cholinergic nerves. The direct effect of VEGF on the density of sensory nerves expressing the transient receptor potential vanilloid subfamily 1 (TRPV1) and cholinergic nerves (ChAT) was studied one week after one or two intravesical instillations of the growth factor. To study the effects of VEGF on bladder function, mice were intravesically instilled with VEGF and urodynamic evaluation was assessed. VEGF-induced alteration in bladder dorsal root ganglion (DRG) neurons was performed on retrogradly labeled urinary bladder afferents by patch-clamp recording of voltage gated $\mathrm{Na}+$ currents. Determination of VEGF-induced changes in sensitivity to abdominal mechanostimulation was performed by application of von Frey filaments.
\end{abstract}

Results: In addition to an overwhelming increase in TRPV1 immunoreactivity, VEGF instillation resulted in an increase in ChAT-directed expression of a fluorescent protein in several layers of the urinary bladder. Intravesical VEGF caused a profound change in the function of the urinary bladder: acute VEGF (1 week post VEGF treatment) reduced micturition pressure and longer treatment (2 weeks post-VEGF instillation) caused a substantial reduction in inter-micturition interval. In addition, intravesical VEGF resulted in an up-regulation of voltage gated $\mathrm{Na}^{+}$ channels (VGSC) in bladder DRG neurons and enhanced abdominal sensitivity to mechanical stimulation.

Conclusions: For the first time, evidence is presented indicating that VEGF instillation into the mouse bladder promotes a significant increase in peripheral nerve density together with alterations in bladder function and visceral sensitivity. The VEGF pathway is being proposed as a key modulator of neural plasticity in the pelvis and enhanced VEGF content may be associated with visceral hyperalgesia, abdominal discomfort, and/or pelvic pain.

\section{Background}

It is highly likely that neurogenic dysfunction of the urinary bladder is involved in various disorders of the lower urinary tract (LUT) including neurogenic bladder, outflow obstruction, idiopathic detrusor instability, overactive bladder, painful bladder syndrome, and diabetic neuropathy. In addition, chronic pathological conditions

\footnotetext{
* Correspondence: ricardo-saban@ouhsc.edu

${ }^{3}$ Department of Physiology, College of Medicine, Urinary Tract Physiological Genomics Laboratory, University of Oklahoma Health Sciences Center (OUHSC), 800 Research Parkway, Room 410, Oklahoma City, OK 73104, USA Full list of author information is available at the end of the article
}

that cause tissue irritation or inflammation can alter the properties of sensory pathways, leading to a reduction in pain threshold and/or an amplification of painful sensation (hyperalgesia) [1].

Depending on the pathology, several mediators and their respective receptors have been proposed to modulate peripheral nerve plasticity in the LUT, including but not limited to: purinergic receptors in general [2] or P2X receptor in particular [3], TRPV1 [1,4], substance $\mathrm{P}$ acting on NK1 receptors [5], protease activated receptors [6], and nerve growth factor and its receptors [7].

\section{Biomed Central}


In this context, the development of cross-sensitization in the pelvis is one of the suggested mechanisms underlying co-morbidity of pelvic disorders which is frequently observed in the clinical setting [8]. Recently, evidence indicated that acute colonic inflammation triggers the occurrence of urinary bladder detrusor instability via activation of the transient receptor potential vanilloid subfamily 1 (TRPV1) related pathways [4]. Moreover, colonic inflammation-induced activation of TRPV1 receptors at the peripheral sensory terminals results in an up-regulation of voltage gated $\mathrm{Na}^{+}$channels on the cell soma of bladder sensory neurons [9]. This increase in channels may underlie the occurrence of peripheral cross-sensitization in the pelvis and functional chronic pelvic pain [9].

The new hypothesis being tested in this manuscript is that increased levels of VEGF observed during bladder inflammation provoke nerve plasticity. This hypothesis is based on evidence indicating that nerves and blood vessels are anatomically associated, follow a common molecular pathway during development, and their maturation in adulthood may be controlled by the same key molecules responsible for their development [10,11]. The finding that mutant mice (neurogenin1/neurogenin2 double knockout embryos) lacking sensory nerves also show disorganized blood vessel branching [12], suggests that local signals such as VEGF supplied by nerve fibers, may provide a cue that determines blood vessel patterning.

Evidence has been presented supporting the hypothesis that many proteins that were originally discovered to be required for axon guidance are implicated in the development of the vascular [11] and lymphatic systems [13]. But perhaps the most striking observation linking the nervous and vascular systems is the finding that angiogenic factors, when deregulated, contribute to various neurological disorders, such as neurodegeneration. The prototypic example of this cross-talk between nerves and vessels is the vascular endothelial growth factor, VEGF [14]. Although originally described as a key angiogenic and permeability factor, it is now well established that VEGF also plays a crucial role in the development of the nervous system [14].

Recently, we provided evidence that chronic inflammation increases the density of bladder sensory nerves that express: a) the transient receptor potential vanilloid subfamily 1 (TRPV1) [15], b) protein gene product (PGP9.5) [16], c) substance $\mathrm{P}$, and d) calcitonin gene-related peptide (CGRP) [17]. We also determined that B20, a VEGF neutralizing antibody, prevented inflammation-induced increase in sensory nerves [17]. Furthermore, instillation of VEGF into the bladder recapitulated the effect of inflammation on sensory nerve plasticity [17], and represents direct evidence of VEGF action on the peripheral nervous system.
The scope of the present work was to determine whether VEGF, in addition to increased sensory nerve density, also alters the density of cholinergic nerves, and, consequently, bladder function and visceral sensitivity.

\section{Results}

Instillation of VEGF into the mouse bladder results in an increase in sensory nerve density

It was reported that VEGF is expressed at relatively higher amounts in nerves than in the surrounding mesenchymal tissue [12]. This finding led to a new appreciation of the role of VEGF in neuronal development $[14,18]$ and stimulated us to review a possible link between VEGF-induced inflammation and bladder nerve plasticity. To provide direct evidence that VEGF induces bladder neuronal plasticity, VEGF was instilled into the C57BL/6 mouse bladder. Previous results from our laboratory indicated that acute or chronic instillation of VEGF into the mouse bladder caused inflammation, characterized predominantly by the accumulation of macrophages [17], and an increase in sensory nerve density as indicated by image analysis of nerve fibers positive for the nociceptive transducer vanilloid type 1 transient receptor potential receptor (TRPV1) [17]. In the present manuscript, we expanded the time course of VEGF exposure by including a group that received two weekly instillations of VEGF. Female C57BL/6 mice were instilled weekly for two weeks with VEGF (6.41 nM in $100 \mu \mathrm{l})$. Mice were euthanized one week after the second VEGF instillation and the bladder was removed for image analysis of TRPV1-positive fibers. One VEGF instillation promotes a substantial increase in TRPV1-positive fibers in the urothelium and lamina propria (Figure 1A) and in the detrusor and adventitia (Figure 1B). Two VEGF instillations resulted in the most pronounced alteration in sensory nerve plasticity, as indicated by a peak increase in TRPV1-positive fibers. After the $4^{\text {th }}$ weekly treatment with VEGF, the response was reduced. Similar results were obtained with ChAT mice indicating that 1 and 2 weekly VEGF instillations provoked similar increases in TRPV1 immune reactivity (data not shown). These results provide direct evidence that VEGF participates in the plasticity of bladder sensory nerves and that two weekly instillations of VEGF produced the largest increase in sensory nerve density.

\section{A mouse model for the study of bladder cholinergic innervation}

We sought to extend our studies by investigating whether VEGF also alters the plasticity of bladder cholinergic nerves. The rationale for the use of the ChATcre mouse model was based on reports that staining 

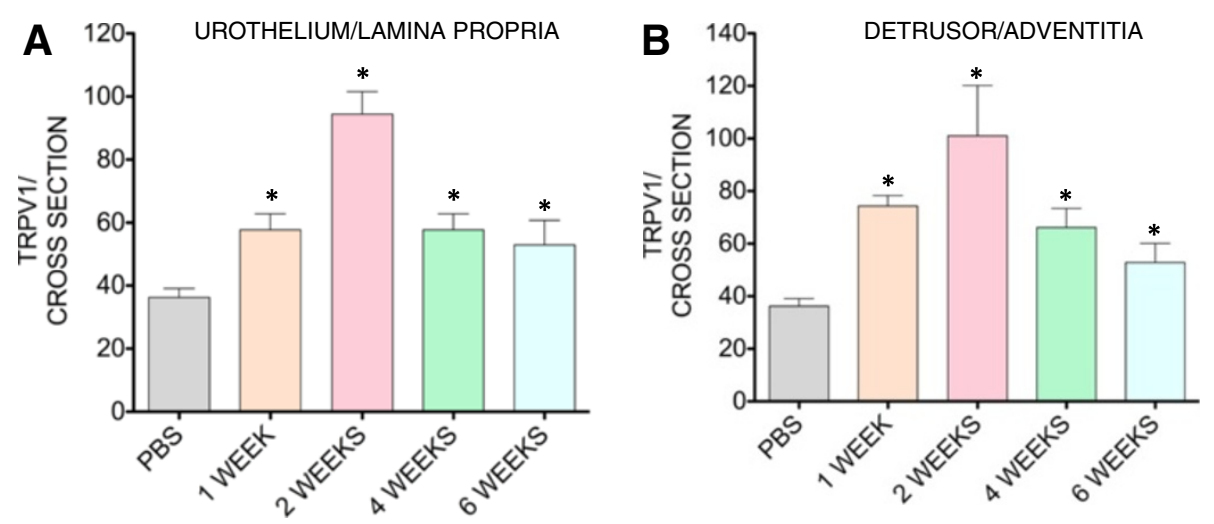

Figure 1 Intravesical instillation of VEGF induces a time-dependent alteration in the density of TRPV1-positive sensory fibers in the urothelium and lamina propria (A) and detrusor and and adventitia (B) layers. Quantification of TRPV1-IR in the C57BL/6 urinary bladder isolated 1 week after: 1, 2, 4, and 6 weekly instillations of VEGF of PBS ( $N=8$ per group). Asterisks indicate a statistically significant difference ( $p$ values $<0.05$ ) when compared to the PBS group.

peripheric nerves with antibodies targeting the synthesizing enzyme choline acetyltransferase (ChAT) is not consistent and often fails to detect these neurons. In contrast, cholinergic neurons and fibers of the urinary bladder and surrounding tissues are readily visualized in whole mount preparations isolated from adult ChAT mice (Figure 2A and 2B). High quality photomicrographs were used to detailed the disctribution of ChAT- positive nerves (Figure 2C, 2D, and 2E). However, using these high quality micrographs, we found the pelvic ganglia to be so intensely fluorescent that the signals from the surrounding tissues were not readily apparent (Figure 2C, red circle). When the fluorescence of the PG region was electronically reduced, it was possible to image the innervation of the colon, uterus, and urinary bladder (Figure 2D). Both preparations also allow the

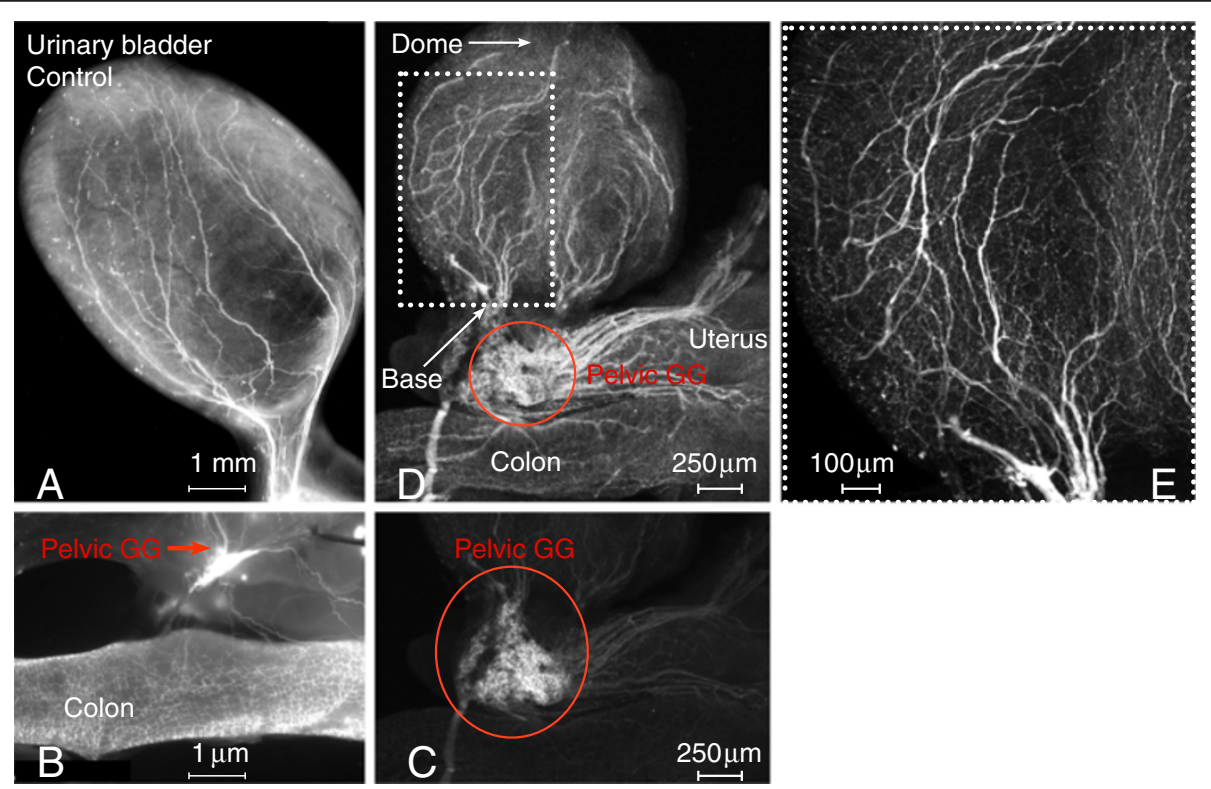

Figure 2 A ChAT transgenic mouse permits the visualization of cholinergic cells and fibers in a pelvic ganglion and cholinergic fibers in the urinary bladder, gastrointestinal tract, and uterus. Representative photomicrographs of whole mount preparations of the urinary bladder removed from ChAT mice instilled with PBS (A). The pelvic ganglion and colon are also illustrated. (B). ChAT nerves appeared intact confirming previous results that intravesical instillation does not cause damage to the bladder wall. C, $\mathbf{D}$, and $\mathbf{E}$ are confocal photomicrographs of whole mount preparations isolated from another control ChAT mouse. An intense fluorescence was observed in the pelvic ganglion region (C). In order to permit visualization of the ChAT-positive fibers in the bladder, uterus, and colon, the intensity of the pelvic ganglion (red circle) was reduced. $\mathbf{E}$ is a high magnification of the area delimited by the white dotted rectangle in figure $\mathbf{D}$ and permits the visualization of large and small cholinergic fibers innervating the urinary bladder. 
visualization of the pelvic ganglia and its relationship with cholinergic nerves innervating the urinary bladder and other pelvic organs (Figure $2 \mathrm{~B}$ and $2 \mathrm{C}$ ), which will permit the capture of these cells for future patch clamp studies. Figure $2 \mathrm{E}$ is a high magnification image of the dotted square region of Figure $2 \mathrm{D}$ and shows the large superficial nerve trunks innervating the adventitial coat. As described in cross-sections presented below, these fibers penetrate deep into the lamina propria and ramify in the urothelium.

In order to confirm that ChAT positive fibers crossing the urinary bladder were indeed nerve fibers, we stained with an antibody targeting the class III $\beta$-tubulin, a specific neuronal marker [19]. Both $\beta$-III tubulin- and ChAT-positive fibers are distributed within the urothelium and detrusor smooth muscle (Figure 3A-D). Areas highlighted by dotted squares in Figure 3D were photographed at higher magnification to discriminate the overlap of the green and red fluorescence in the urothelium
(Figure 3E-H) and detrusor smooth muscle (Figure 3I-L). These images indicate substantial overlap between the cholinergic and tubulin markers and thus show that the cholinergic fibers are indeed neuronal.

An analysis of images from sections shows the relative density of ChAT fluorescent fibers in the urothelium, lamina propria (sub-urothelium), detrusor muscle, and adventitia in comparison with areas immunostained by a pan-neuronal marker (PGP9.5), sensory nerves (TRPV1), and substance P containing fibers (Figure 4). It has to be noted that PGP9.5 antibodies resulted in a non-specific labeling of the urothelial layer. A reasonable explanation for this artifact is that the methods recommended for permeabilization of the tissues caused such labeling. These findings precluded the use of the urothelium for quantification purposes of PGP9.5 but not for TRPV1 and SP. PGP9.5 image analysis was performed in two layers: the detrusor smooth muscle and the suburothelium that extended from the basal layer of the

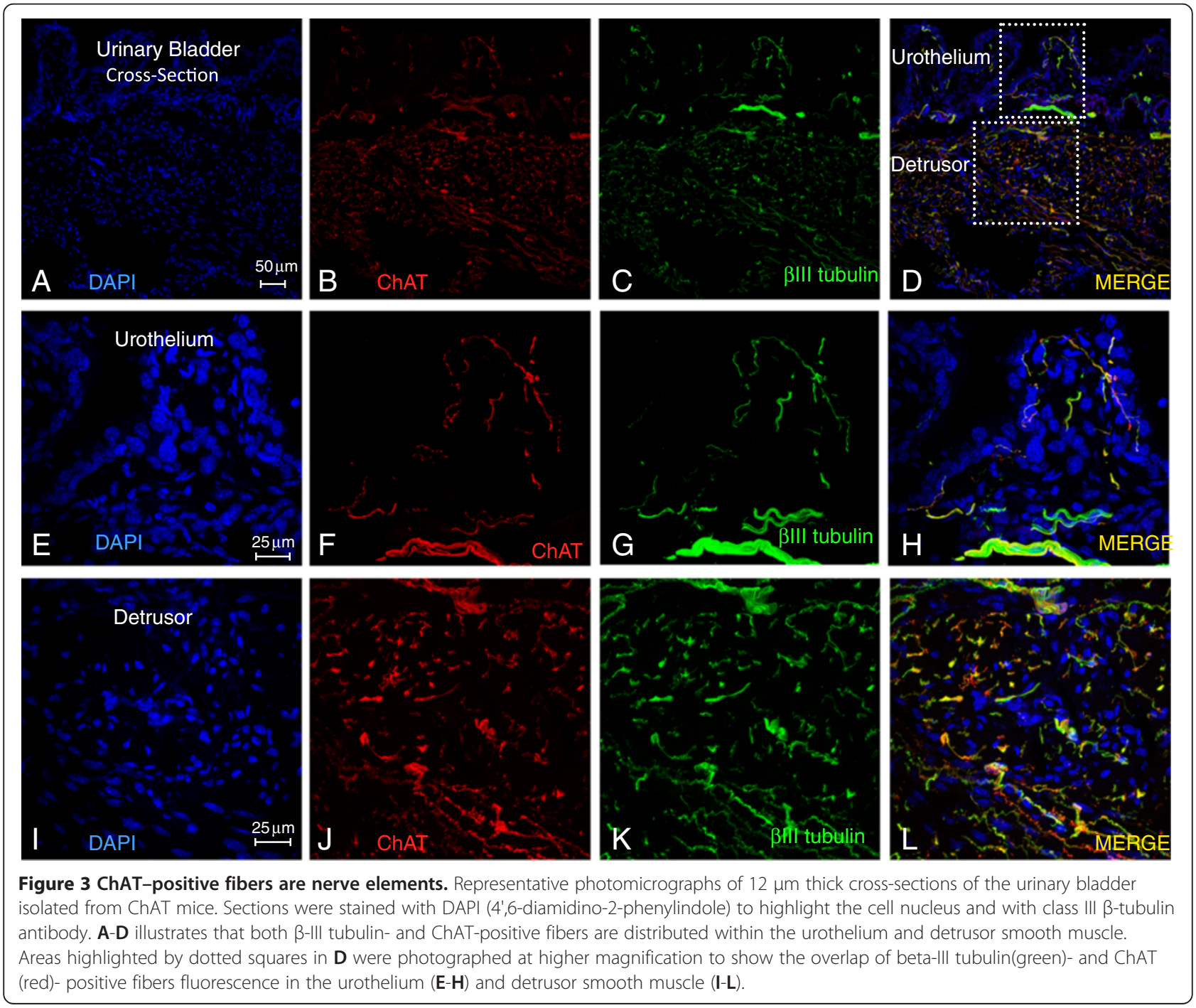




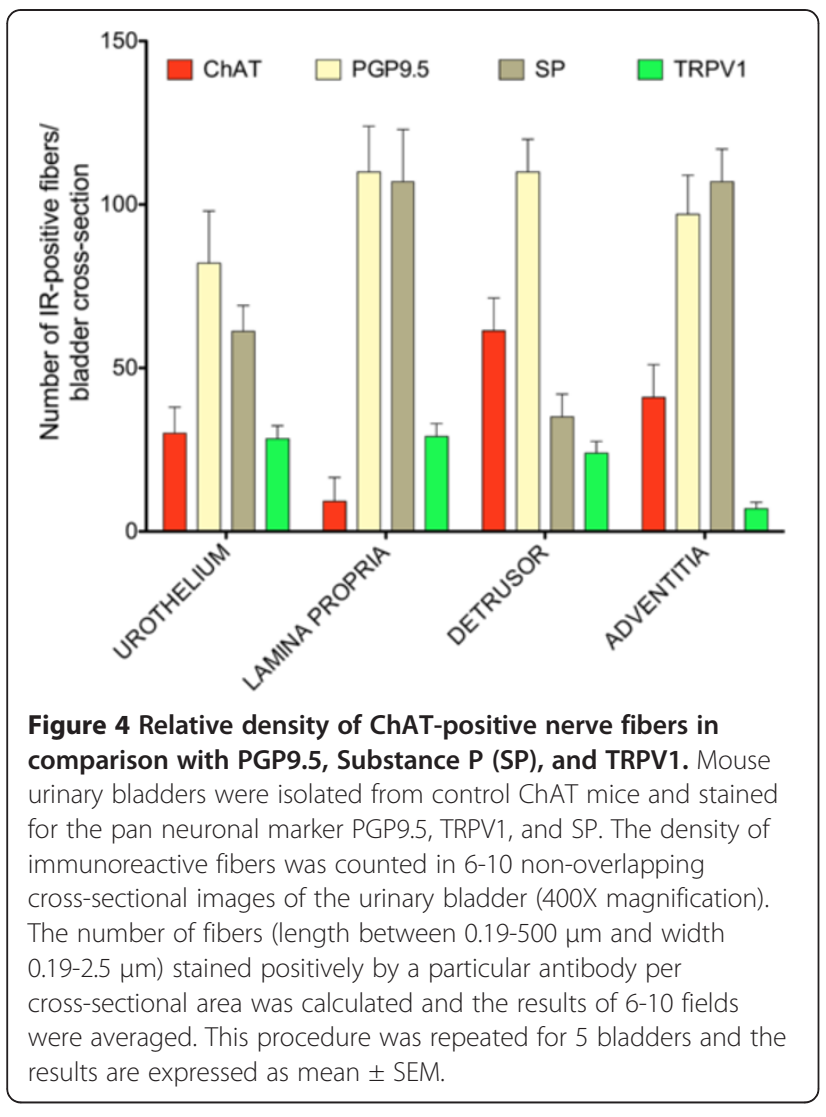

urothelium to detrusor. Overall, these results indicate ChAT nerves are more prominent in the detrusor muscle when compared to TRPV1 nerves, whereas, TRPV1 nerves are more prominent than ChAT nerves in the lamina propria.

The finding that both sensory (TRPV1-positive) and cholinergic nerves are involved in urinary tract disorders such as overactive bladders [20] raises the question of whether these two systems are anatomically distinct. Therefore, we sought to determine whether sensory and motor nerves are co-localized in urinary bladder. Using bladder whole mounts that underwent blunt dissection to separate the lamina propria from the detrusor (Figure 5), we observed that TRPV1 and ChAT signals appear to overlap in the lamina propria (yellow arrow on Figure 5D) and to a lesser degree in the detrusor smooth muscle (Figure 5H). However, high magnification photomicrographs (Figures 5I-L) indicate that the two types of fibers are separate and run adjacent to each other, primarily around the blood vessels (Figure 5L). Photomicrographs of bladder cross-sections confirm the results obtained with whole mounts (Figure 6D). In addition, higher magnification images illustrate the separation of TRPV1 and ChAT fibers in intramural ganglia (Figure $6 \mathrm{H}$ ) as well as in the lamina propria (Figure 6L). We conclude that the sensory and motor components do not overlap.

\section{VEGF instillation increases the number of ChAT positive fibers}

Figure 7 contains representative photomicrographs of urinary bladders isolated from control and VEGF-treated ChAT mice. These cross-sections suggest that VEGF treatment resulted in an increased density of ChAT(Figure 7B and 7E) and TRPV1- positive fibers (Figure 7C and 7F). For better appreciation of sensory and cholinergic nerves, merged microphotographs were digitally amplified and are presented on Figure $7 \mathrm{G}$ and $7 \mathrm{H}$ (note the calibration bar on Figures $7 \mathrm{G}$ and $\mathrm{H}$ and compare with the bars on Figures 7A and D). Image analysis of nerve density indicates that single or repeated challenge of mouse bladders with VEGF resulted in a significant increase in ChAT density in the urothelium, lamina propria, and detrusor smooth muscle (Figure 8). Together these results indicate that in addition to alterations of peripheral sensory nerve plasticity (Figure 1), direct administration of VEGF also promotes an increase in bladder cholinergic nerve plasticity.

\section{Urodynamic analysis of bladder function after intravesical VEGF instillation in awake (unrestrained) mice}

To evaluate the effects of intravesical VEGF on urodynamic parameters and function of the urinary bladder in vivo, we performed cystometric assessment in conscious mice. Micturition cycles were first recorded under control conditions $(\mathrm{N}=5)$ and served as a baseline (internal control) followed by urodynamic evaluation at 1 and 2 weeks after beginning VEGF treatment. Figure 9 shows raw cystometric traces recorded in the same animal before (Figure 9A, baseline) and 2 weeks after intravesical VEGF (Figure 9B). Urodynamic parameters were first compared to the baseline for each mouse followed by further comparisons between the groups (before and after treatment). Intravesical VEGF caused significant changes in the function of the urinary bladder over the course of treatment (Figure 9B).

At 1 week post-VEGF, significant changes included a reduction in micturition pressure $(19.75 \pm 0.53 \mathrm{mmHg}$ at baseline $v s 14.4 \pm 0.32 \mathrm{mmHg}$ at 1 week, (Figure 10B, $\mathrm{p} \leq 0.005$ ) and decreased micturition volume (by $26 \%$ in comparison to baseline, $(\mathrm{p} \leq 0.001$, Figure $10 \mathrm{C})$. These parameters were also significantly reduced 2 weeks after the initiation of VEGF treatment. Longer treatment (2 weeks) caused a substantial reduction in inter-micturition interval from $341.2 \pm 25.6 \mathrm{~s}$ to $188.0 \pm 20.8 \mathrm{~s}(\mathrm{p} \leq 0.001$, Figure $10 \mathrm{~A})$ and a decrease in bladder capacity from $57.1 \pm 4.3 \mu \mathrm{l}$ to $31.6 \pm 3.5 \mu \mathrm{l}(\mathrm{p} \leq 0.001$, Figure 10D). There was a tendency towards an increase in the number of non-micturition contractions (pointed by arrows in Figure 9B) after intravesical VEGF, although the difference did not reach statistical significance (Figure 10E). Other cystometric parameters such as intermicturition pressure interval, 


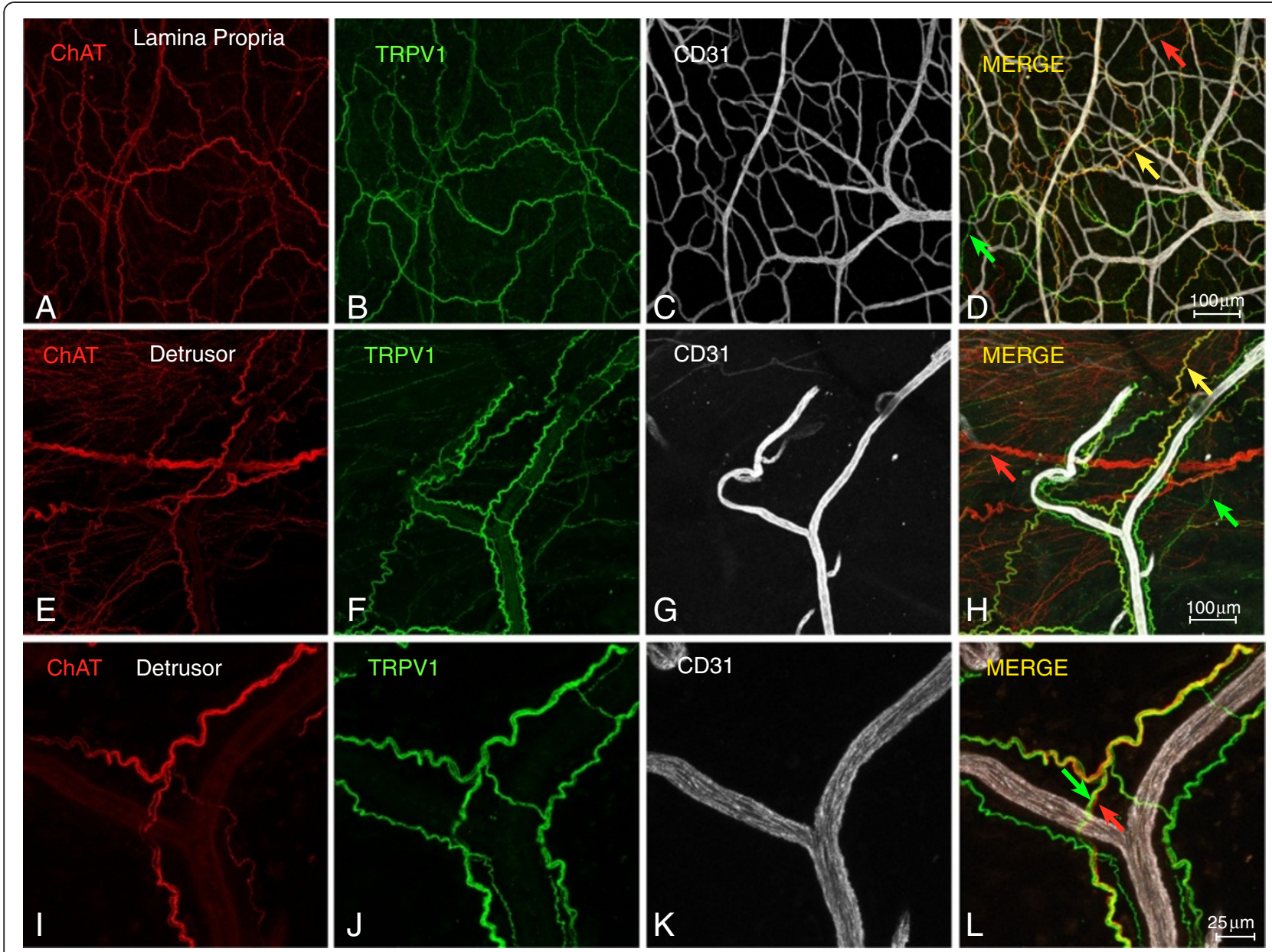

Figure 5 Representative photomicrographs of bladder whole mounts showing ChAT-positive nerve fibers, sensory nerves (TRPV1), and blood vessels (CD31). Representative photomicrographs taken from bladders isolated from ChAT mice and prepared as whole mounts that underwent blunt dissection to separate the lamina propria from the detrusor. In the lamina propria (D) the ChAT and TRPV1 fibers are usually associated (yellow arrow) but sometimes take separate paths (red and green arrows). In the detrusor (H) ChAt-positive fibers dominate although the ChAT and TRPV1 fibers around blood vessels are usually associated (yellow arrow). High magnification microphotographs (I-L) indicate that the two type of fibers run adjacent to each other (L).

threshold pressure and basal pressure were unaltered by VEGF treatment. Additional group of mice $(\mathrm{N}=5)$ underwent intravesical instillations with PBS and cystometric parameters were recorded at the same time points as in the VEGF group. Intravesical PBS did not significantly affect the function of the urinary bladder (Figure 10A-E). In addition, the baseline values did not differed between the PBS and VEGF groups and, therefore, baseline values were combined in Figure 10.

Intravesical VEGF caused an up-regulation of voltage gated $\mathrm{Na}^{+}$channels (VGSC) in bladder DRG neurons It is well established that bladder inflammation causes an increase in VGSC expressed in sensory neurons receiving input from the urinary bladder [21]. In this set of experiments we aimed to determine if intravesical VEGF would cause any changes in VGSC, thereby, affecting neuronal excitability of bladder projecting afferents.

Retrograde labeling of lumbosacral sensory neurons with Fast Blue allowed identification of bladder projecting DRG cells used for electrophysiological recordings and data analysis. Bladder inflammation caused by intravesical VEGF triggered an increase in the amplitude of total $\mathrm{Na}^{+}$current recorded from bladder afferent neurons. Representative raw recordings of total $\mathrm{Na}^{+}$current obtained from the control (intravesical PBS) and experimental (intravesical VEGF) groups are presented in Figure 11A. The current-voltage (I-V) relationship of total $\mathrm{Na}^{+}$current normalized to the cell size shows that these neurons produced a large amplitude $\mathrm{Na}^{+}$current upon membrane depolarization, reaching maximal amplitude at $-20 \mathrm{mV}$ (Figure 11B). VEGF application increased the peak amplitude of total $\mathrm{Na}^{+}$current in bladder DRG 


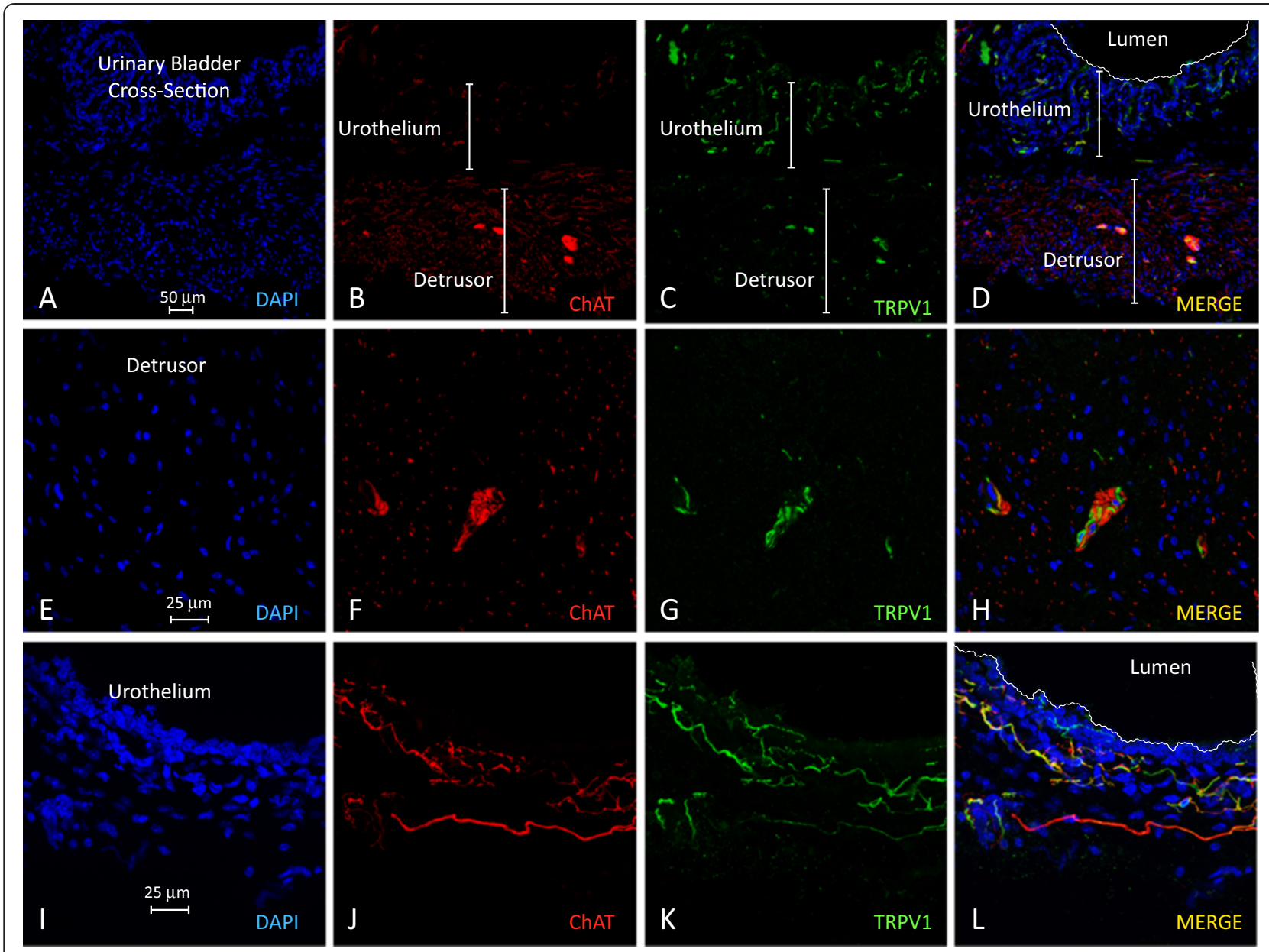

Figure 6 Photomicrographs of bladder cross-sections confirm the results obtained with whole mounts and indicate the predominance of TRPV1 fibers in the urothelium and the predominance of ChAT fibers in the detrusor smooth muscle. A-D are representative

photomicrographs of the entire bladder cross section. $\mathbf{E}-\mathbf{H}$ are representative photomicrographs of the detrusor smooth muscle taken at high magnification to show some areas of overlap between ChAT and TRPV1, primarily in intramural fascicles $(\mathbf{H})$. $\mathbf{I}-\mathbf{L}$ are representative

photomicrographs of bladder urothelium taken at high magnification to show some areas of overlap between ChAT and TRPV1, primarily in the lamina propria (sub urothelium), as illustrate (L).

neurons at $-10 \mathrm{mV}$ from $-152.1 \pm 16.8 \mathrm{pA} / \mathrm{pF}(\mathrm{n}=11)$ in the control group to $-253.5 \pm 43.5 \mathrm{pA} / \mathrm{pF}(\mathrm{n}=9)$ in the VEGF group $(\mathrm{p} \leq 0.05)$. Significant enhancement of total $\mathrm{Na}^{+}$ current was observed at all voltages from $-30 \mathrm{mV}$ to +20 $\mathrm{mV}$ (Figure 11B).

We next assessed the kinetic parameters of total $\mathrm{Na}^{+}$ currents after the induction of neurogenic bladder inflammation caused by VEGF. The steady-state activation was studied by using a three-pulse protocol with a negative pre-pulse to $-110 \mathrm{mV}$ and a series of short depolarizing pulses (10 ms duration) to activate $\mathrm{Na}^{+}$currents (Figure 12A, top panel). The amplitude of steady-state activation was measured at the peak of tail current upon the voltage step to $-70 \mathrm{mV}$, normalized and plotted as $\mathrm{I} / \mathrm{I}_{\max }$ against the voltage (Figure 12A, lower panel). Intravesical VEGF led to the leftward shift in the steadystate activation of total $\mathrm{Na}^{+}$current by $8 \mathrm{mV}\left(\mathrm{V}_{1 / 2}=-19.9\right.$ $\pm 2.6 \mathrm{mV}$ in the control group $v s-27.6 \pm 2.0 \mathrm{mV}$ at 2 weeks of treatment, Figure 12B, $\mathrm{p} \leq 0.05$ ). The amplitude of steady-state inactivation was measured at a series of membrane depolarizing steps ranging from $-100 \mathrm{mV}$ to +70 $\mathrm{mV}$ (Figure 12C). Bladder inflammation did not affect the parameters of steady-state inactivation of total $\mathrm{Na}^{+}$ current in bladder sensory neurons (Figure 12D).

\section{VEGF triggered an enhanced abdominal sensitivity to} mechanical stimulation with von Frey filaments

Abdominal sensitivity was tested in a separate group of mice $(\mathrm{N}=7)$ before and after bladder treatments with VEGF. Figure 13 summarizes the frequency of responses to von Frey filament testing in the lower abdominal area before, and 1 week and 2 weeks after intravesical instillations of VEGF in the same group of mice. The response frequency correlated with the applied force, reaching a 


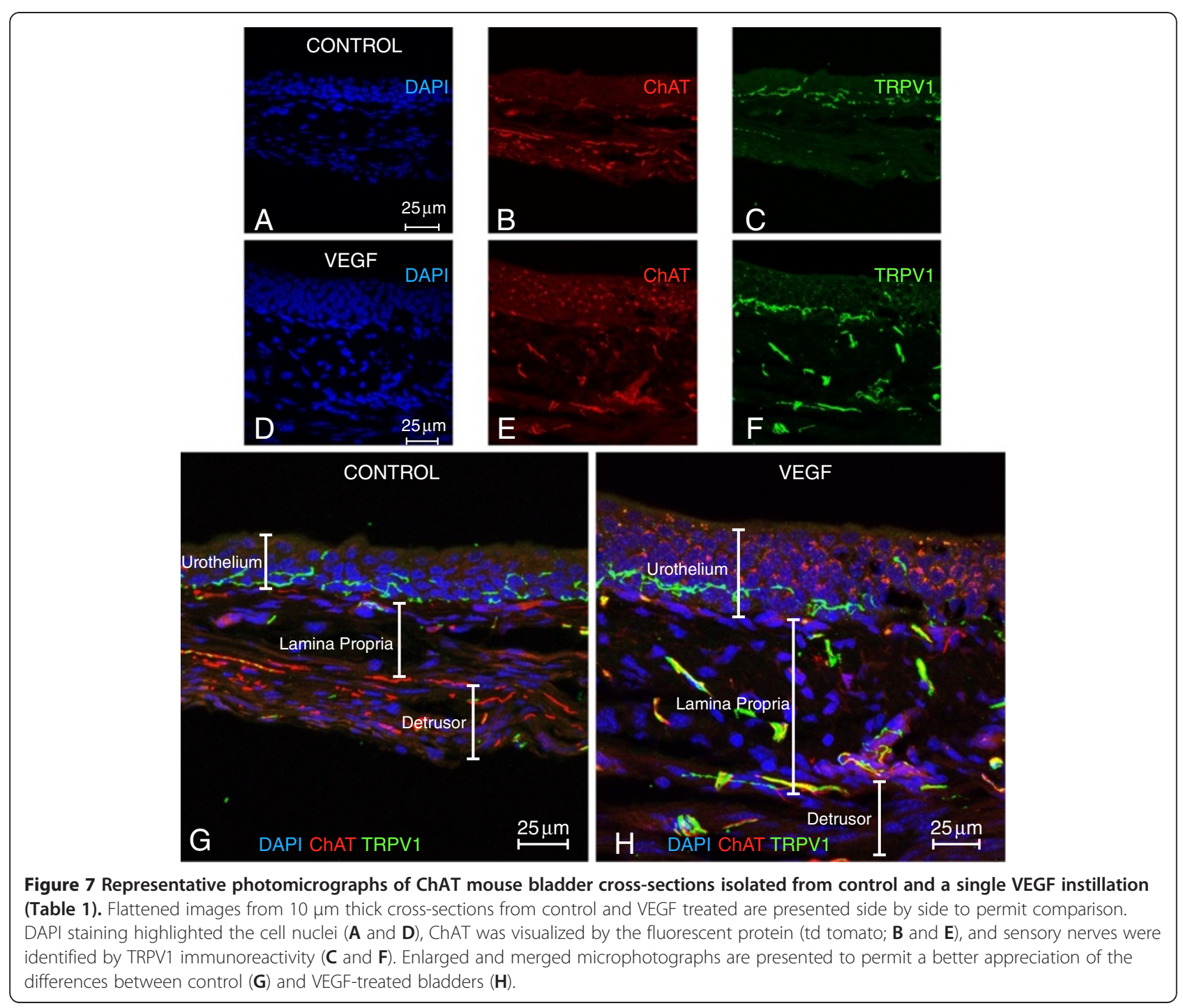

plateau of $20 \%$ at the maximal tested force of $4 \mathrm{~g}$ (Figure 13). One week after VEGF treatment, mice became more sensitive to the filament testing and responses reached more than $40 \%$ at lower forces of $0.16 \mathrm{~g}$ and $0.4 \mathrm{~g}$ (Figure 13, $\mathrm{p} \leq 0.05$ to baseline). Two weeks after the treatment the frequency response showed significant differences with stimuli of 1 and $4 \mathrm{~g}$ filaments in comparison to 1 week (Figure 13, p $\leq 0.05$ to baseline).

These results provide evidence that intravesical VEGF leads to an increased viscerosomatic response to cutaneous stimulation in the pelvic region. Such a response is usually associated with abdominal discomfort and/or pelvic pain.

\section{Discussion}

The major findings of the present manuscript are: 1) the instillation of VEGF produces an increase in sensory nerve density, presumably by nerve sprouting, that reaches a maximum at 2 weeks and declines by 4 weeks; 2) in addition to significant increase in sensory nerve fibers, VEGF increases the density of bladder cholinergic nerve fibers; and 3) the increase in nerve density produced by VEGF results in altered bladder function and visceral sensitivity. The unique feature of our findings is that VEGF produces an increase in nerve density via urothelium.

The nervous and vascular systems share several anatomical parallels. Both systems utilize a complex branching network of neuronal cells or blood vessels reaching all regions of the body. The anatomical similarity of the nervous and vascular systems suggests that axons might guide blood vessels and vice-versa [22]. Indeed, signal molecules produced by peripheral neuronal cells, such as VEGF [12], guide blood vessels [14] and signals from vessels, such as the neurotrophins NGF and NT-3, are required for, and orchestrate extension of neurons adjacent to vessels [23]. In this manner, the neuronal and 


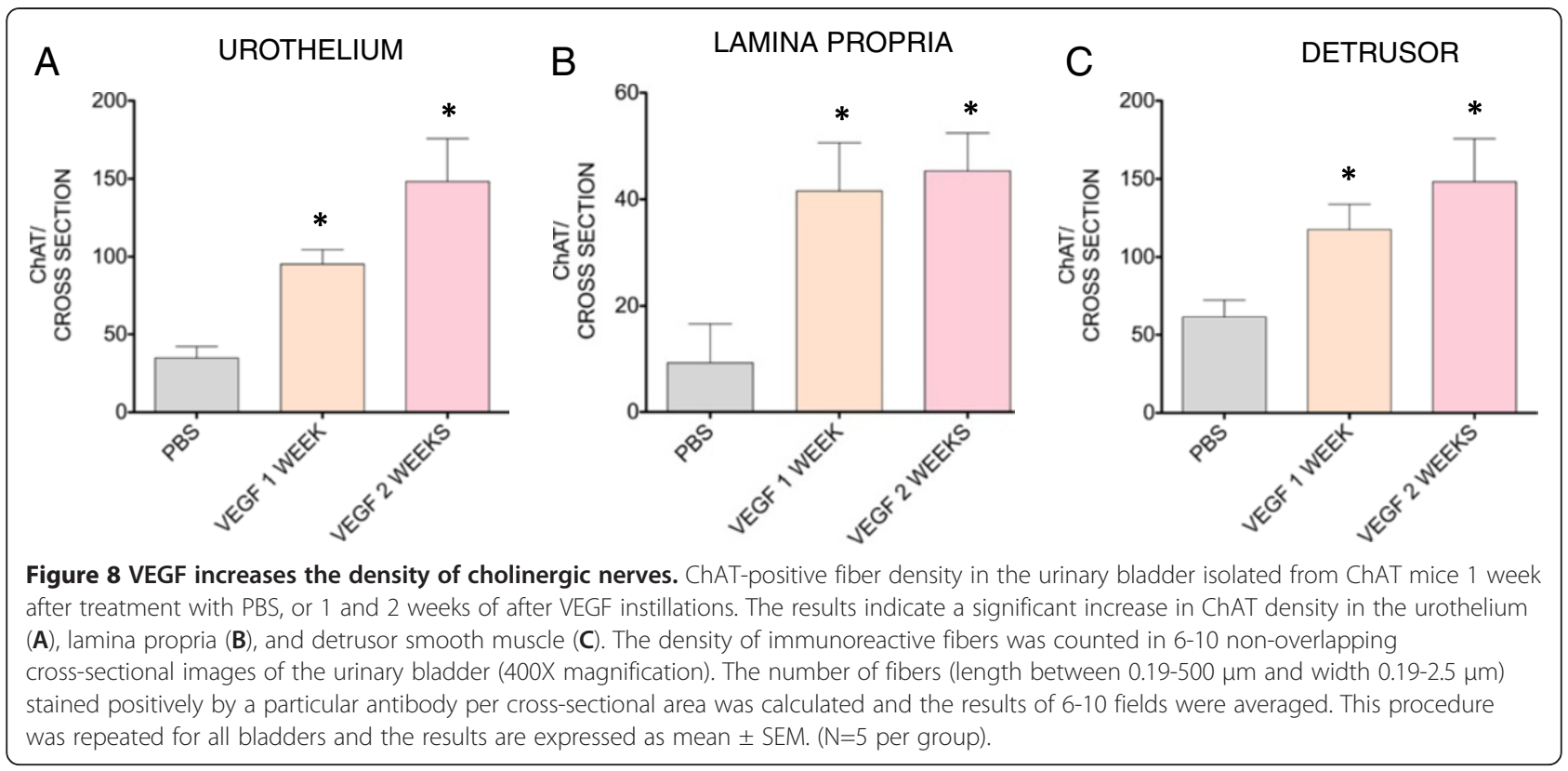

vascular systems are well organized and coordinated in normal adult tissues. However, in chronic inflammatory states particularly in the LUT, little is known about how the nerve-vessel relationship functions and whether it could underlie the chronic pain syndrome observed in patients with disorders of the lower urinary tract. In this context, this manuscript presents a body of evidence implicating VEGF signaling in the enhanced innervation of the urinary bladders in mice and the consequent alteration in mechanical responses and visceral sensitivity.

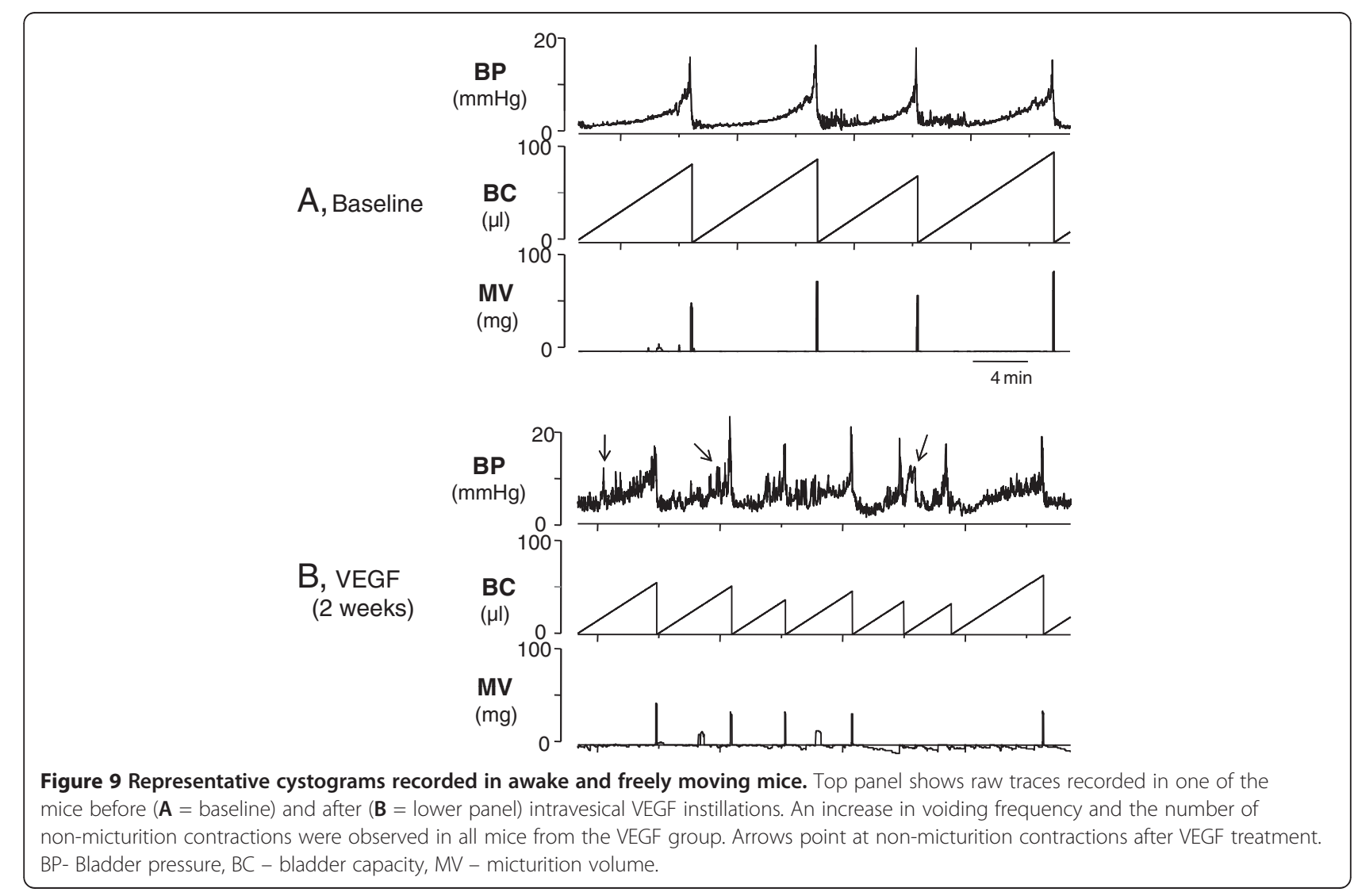



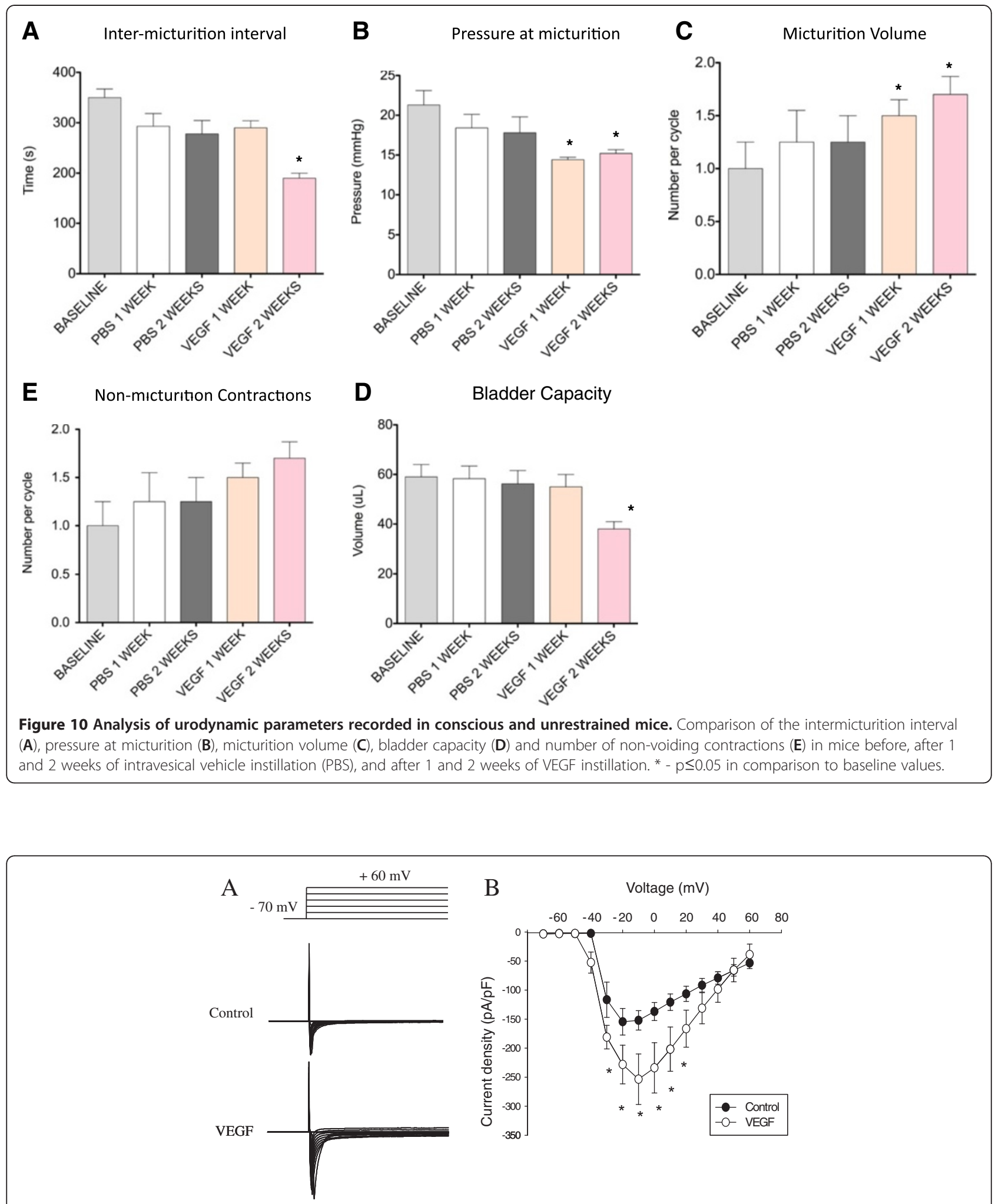

Figure 11 The amplitude of voltage-gated $\mathrm{Na}^{+}$currents is increased in bladder sensory neurons isolated from VEGF-treated mice.

A, Top panel presents the scheme of voltage protocol for recordings of voltage gated $\mathrm{Na}^{+}$currents including depolarizing pulses from -70 $\mathrm{mV}$ to $+60 \mathrm{mV}$ ( $10 \mathrm{mV}$ increments) from the holding potential of $-70 \mathrm{mV}$. Lower panel shows representative raw traces recorded from VEGF group 2 weeks after the beginning of the treatment. B, Current-voltage $(\mathrm{I}-\mathrm{V})$ relationship of the total $\mathrm{Na}^{+}$current recorded in bladder DRG neurons after intravesical application of VEGF (2 weeks). * - $\mathrm{p} \leq 0.05$ when compared to control group. 


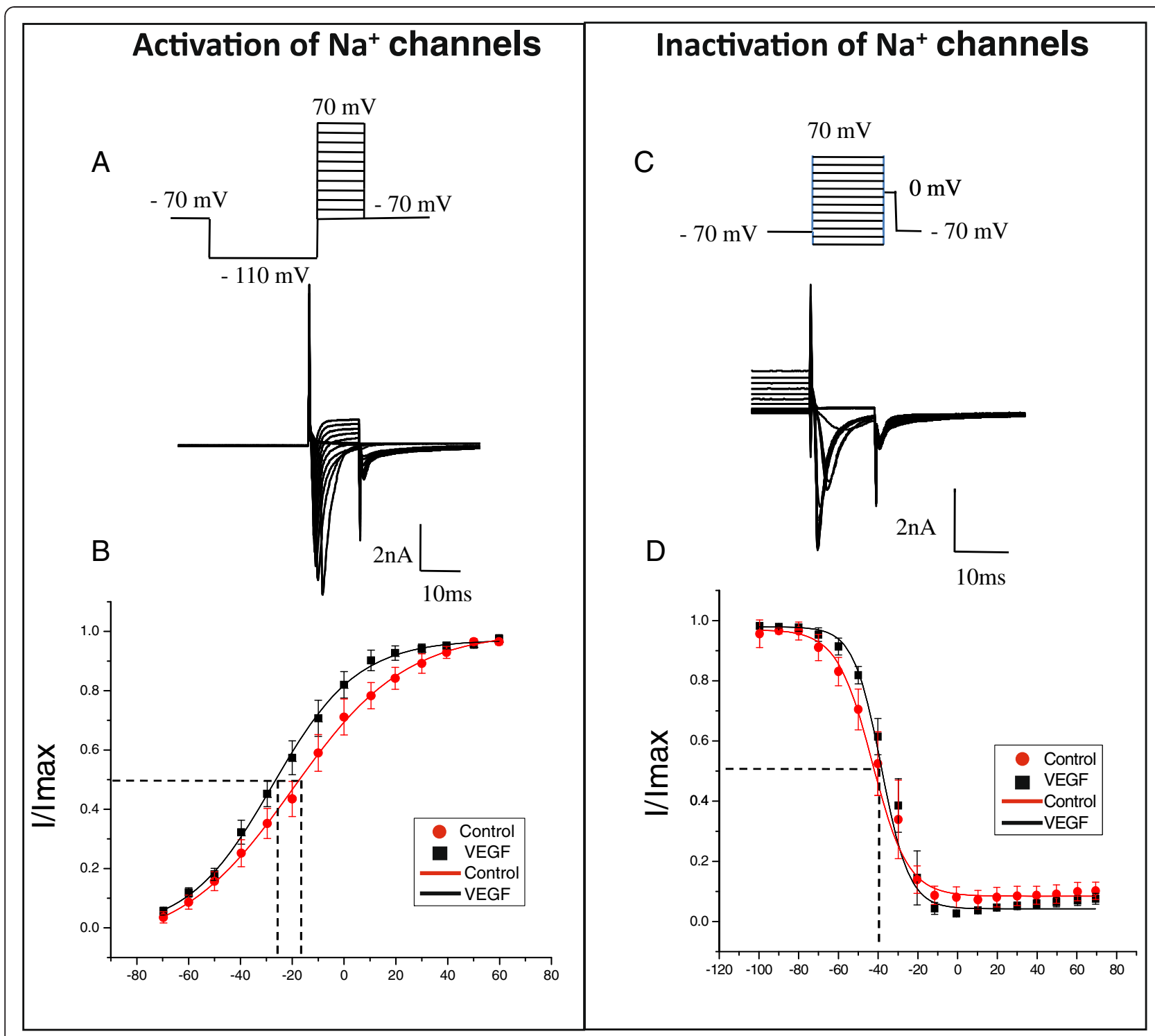

Figure 12 Kinetics of voltage gated $\mathrm{Na}^{+}$channels recorded in bladder DRG neurons. A: The protocol (top panel) of steady-state activation and raw traces (bottom panel) of total $\mathrm{Na}^{+}$current. The steady-state activation of VGSC was assessed by using a three-pulse protocol with a negative pre-pulse to $-110 \mathrm{mV}$ and a series of short pulses of $10 \mathrm{~ms}$ duration from $-110 \mathrm{mV}$ to $+70 \mathrm{mV}$ to activate Na+ currents. B: Voltage dependence of steady-state activation in bladder neurons from control and VEGF treated animals. Please note a leftward shift in the group with VEGF instillations suggestive of channel opening at more negative potentials. C: The protocol of steady-state inactivation (top panel) and raw traces of the recorded $\mathrm{Na}^{+}$current (bottom panel). The amplitude of steady-state inactivation was measured at $0 \mathrm{mV}$ after $150 \mathrm{~ms}$ depolarizing pulses ranging from $-100 \mathrm{mV}$ to $70 \mathrm{mV}$. D: Voltage dependence of steady-state inactivation of $\mathrm{Na}^{+}$channels in lumbosacral bladder DRG neurons was not different in the control group and VEGF-treated mice.

Interest in guidance molecules, and particularly VEGF, modulating both vascular and neuronal pathology is emerging [14]. Changes in VEGF levels are associated with alterations in the vascular system of the urinary bladder [17]. VEGF is increased in bladders of patients with painful bladder syndrome, and this increase is associated with glomerulations on hydrodistension [24]. However, increased bladder VEGF is not observed in patients who do not show petechial bleeding or in controls [24], suggesting that VEGF levels are associated with those PBS patients exhibiting alterations in the bladder microvascular system.

At this moment, it is not readily apparent which of the VEGF receptor subtypes mediates the bladder neuroplasticity in the mouse model. Both VEGFR1 and VEGFR2 as well as NRP1 and NRP2 are highly expressed in urothelium and intramural ganglia [25]. We also reported that control human bladders urothelium present a predominance of VEGFR1 and NRP2 over VEGFR2 and NRP1 immunoreactivity and that PBS 


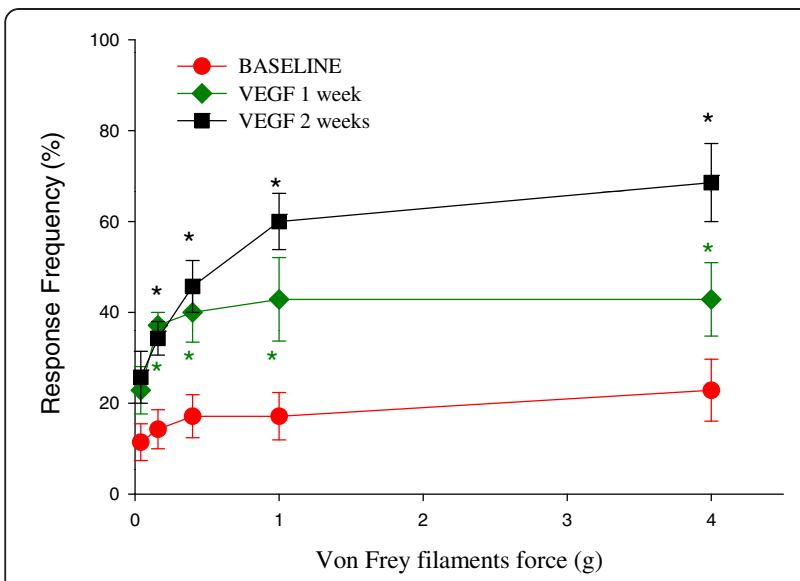

Figure 13 VEGF triggered an enhanced abdominal sensitivity in response to mechanical stimulation with von Frey filaments. Effects of intravesical VEGF on the development of viscerosomatic hyperalgesia as measured by the response to mechanical stimulation of the lower abdominal area using von Frey filaments. * ${ }^{*} \leq \leq 0.05$ when compared to the control group. This data suggests that intravesical VEGF induced the development of abdominal hypersensitivity in pelvic area which could be a reflection of abdominal discomfort/pain.

patients present a decrease in VEGFR1 and NRP2 expression [26]. Nevertheless, our results strongly suggest a new and blossoming VEGF-driven processes in the bladder that may be a putative target in neuronal plasticity. However, the role of VEGF pathway in bladder neuroplasticity is in its infancy. In contrast, the roles of NGF and BNDF in neuroplasticity are well established in bladder pathology (e.g., due to spinal cord injury) and have resulted in the testing of NGF-/BNDF-antibodies (or siRNA knockdown) as possible therapeutic options. Therefore, it is tempting to propose that VEGF neutralizing antibodies, such as avastin, or VEGF receptor antagonists may be of benefit to reduce inflammationinduced bladder neuronal plasticity. However, it has to be kept in mind that this growth factor is necessary not only for developing vessels and angiogenesis but also VEGF signaling is required for vascular homeostasis [27] and the consequences of reduced levels of VEGF can impact the kidney vasculature as seen in pre- eclampsia [28]. A promising alternative for neutralization of VEGF seems to be the blockade of neuropilins by engineered antibodies [29]. However, it is too early to predict whether neutralization of neuropilins will have any deleterious effect on the established vasculature.

The rationale for the methodology employed here is based upon our previous observations that VEGF is taken up by the intact urothelium. We showed that following intravesical instillation of a fluorescent VEGF tracer (scVEGF/Cy5.5) which only internalizes in cells expressing active VEGF receptors [30], results in accumulation of this growth factor in suburothelial layers
[31,32]. After binding these receptors, VEGF may be transcytosed by the urothelial cells into deeper suburothelial layers. Alternatively, VEGF could affect the permeability of the urothelium through mechanisms reminiscent of VEGF's effects on vascular permeability, which results in paracellular transport of VEGF. Indeed, the protein constituents comprising this highly effective urothelial barrier (tight junctions), occludins [33], claudins [34], and zonula occludens-1 [35] have been recently studied in detail [36] and are known targets of VEGF-mediated effects on vascular permeability. After the uptake, VEGF produces both bladder inflammation and changes in neuronal plasticity [17]. The hypothesis that VEGF is taken up by the urothelium was substantiated by the following findings: 1- VEGF receptors are expressed in the mouse [32] and human bladders [31]; 2-VEGF neutralizing antibodies significantly reduced inflammation and neuronal plasticity induced by intravesical Bacillus Calmette-Guérin (BCG) stimulation [17]; 3- An antibody targeting neuropilins (VEGF co-receptors) reduces bladder inflammation [37]; 4- VEGF itself reproduced the findings obtained with BCG by causing bladder inflammation and sensory nerve plasticity [17].

\section{Increase in cholinergic fibers}

Although an increase in sensory nerve density, particularly those expressing TRPV1-IR, has been proposed to underlie pain sensation and neurogenic detrusor overactivity [38], our past work did not explore whether the increased nerve density also resulted in altered function [17]. In order to investigate motor nerves, we used a unique mouse model expressing a fluorescent protein under the endogenous Chat gene promoter, we present evidence that direct application of VEGF into the mouse bladder increases the density of peripheral cholinergic nerves. To the best of our knowledge this increase in cholinergic nerve fibers represents a new finding that was only possible by the use this ChAT transgenic mouse, a model which will open a new area of research on the role of VEGF and its receptors in bladder motor function.

\section{How does VEGF produce its effects?}

VEGF and its receptors are known neuronal guidance molecules and, therefore, it is expected that they affect nerves. However, the inflammation induced by VEGF may be another possible mechanism leading to an increase in neuronal density. Indeed, VEGF mediates inflammation in the bladder as shown by the findings that instillation of VEGF causes vasodilation, edema, and macrophage recruitment, hallmarks of inflammation [17], while application of neutralizing VEGF antibodies significantly reduce bladder inflammation [37]. At this time, there is no definitive evidence suggesting a specific 
inflammatory cell regulating bladder nerve plasticity. However, given the known trophic effects of VEGF on neurite growth prolonged survival of neurons [39,40], and reinnervation following local nerve damage [41,42], it is reasonable to propose that inflammatory cells producing VEGF may mediate these growth effects on neurons. This new appreciation of VEGF signaling in bladder inflammation is supported by emerging evidence that VEGF is increased at the site of inflammation, and that infiltrating lymphocytes and other inflammatory cells may represent additional sources of VEGF [43]. The involvement of cholinergic nerves on bladder inflammatory responses to VEGF suggests a cross-talk between the autonomic and immune systems. Whether the immune system is functionally and anatomically connected to the bladder nervous system remains to be determined. However, a recent investigation proposes that afferent and efferent signals transmitted in the vagus nerve modulate innate immune responses and are components of an inflammatory reflex $[44,45]$. Therefore, it is fair to propose that VEGF increases the crosstalk between the immune and autonomic systems.

\section{VEGF alters bladder function}

We showed for the first time that VEGF affects bladder function and modulates micturition reflex pathways.

Analysis of urodynamic parameters recorded in conscious mice confirmed the suggested role of VEGF in modulation of micturition reflex pathways. It is known that exogenous VEGF (or hypoxia induced upregulation of the growth factor) can lead to detrusor and urothelial hypertrophy and hyperplasia [46]. In addition, previous immunohistochemical analyses of human specimens detected increased innervation in the suburothelial and detrusor layers of the urinary bladder in PBS patients $[47,48]$. In our mouse model, we established that intravesical VEGF treatment resulted in an increase in the density of ChAT fibers in both the detrusor smooth muscle and urothelial layers. This increase in nerve density was associated with altered bladder function as indicated by a decrease in the duration of intermicturition interval, reduced voiding pressure, micturition volume and bladder capacity during continuous filling cystometry. At this time, the individual contributions of sensory and motor nerves to the VEGF-induced increased bladder motility are not clear. Blockade of TRPV1 with capsazepine may shed some light in this respect.

Our results are consistent with other studies which established similar urodynamic changes in animal models of bladder irritation/inflammation [49-51]. For instance, overexpression of neurotrophic nerve growth factor (NGF), a well-known modulator of neural plasticity, in the urinary bladder of mice caused bladder hyperreflexia associated with increased voiding frequency $[7,52]$. These changes were accompanied by an increased density of calcitonin gene-related peptide, SP and neurofilament (NF) 100 positive fibers, as well as tyrosine hydroxylasepositive sympathetic nerve fibers within the suburothelial nerve plexus of the urinary bladder [7]. Additionally, expression of several TRP channels, including TRPA1, TRPV1, and TRPV4, was increased in the urinary bladder of mice over-expressing NGF [53]. Interestingly, the urinary bladder phenotype observed in mice with urothelial overexpression of NGF was associated predominantly with the afferent limb of the micturition reflex, whereas our results provide evidence that VEGF affects both afferent and efferent neural pathways. Our data confirmed the suggestion that VEGF may be a potent modulator of neural plasticity in the LUT. Other investigators also suggested that VEGF is a more potent stimulator of neuronal plasticity compared to a number of different neurothrophic factors [54-56]. However, a cross-talk between VEGF and neurotrophins cannot be discarded. On one hand administration of VEGF can support and enhance the growth of regenerating nerve fibers, probably through a combination of angiogenic, neurotrophic, and neuroprotective effects [57] and conversely, neurotrophins, such as NGF have been described as pro-angiogenic factors [58]. On the other hand VEGF had neurotrophic effects comparable with BDNF, NT3, or NT4 on the rat isolated pelvic ganglia in culture, [54]. In addition, VEGF was found to be more potent than BDNF in inducing ChAT-expressing fibers $[54,55]$. Moreover, the synergistic biological activity of VEGF and NGF [59] is supported by the finding that mechanical stretch of sympathetic neurons seems to induce VEGF expression via a NGF and CNTF signaling pathway [60]. An intriguing recent hypothesis explaining the cross-talk between VEGF and neurotrophins proposes the convergence of putative signaling downstream of receptor tyrosine kinases [61]. In this work, Kidins220 /ARMS (Ankyrin repeat-rich membrane spanning) was identified as a main player in the modulation of neurotrophin and VEGF signaling in vivo, and a primary determinant for neuronal and cardiovascular development [61]. In support of this hypothesis, it was demonstrated that Kidins220 interacts with neurotrophin, VEGF, ephrin, and glutamate receptors, and is a common downstream target of several trophic stimuli [61,62]. Adding to the cross-talk between neurotrophins and VEGF on neuronal plasticity, the present results go one step further by indicating that VEGF alters both sensory (TRPV1) as well as motor (ChAT) nerves. Our present results suggest the idea that across-talk between VEGF and neurothropins controls bladder motor (ChAT) nerve plasticity.

Electrophysiological recordings in vitro and in vivo revealed several distinct classes of afferent fibers that participate in transmission of sensory signaling upon 
physiological bladder filling, noxious distension, chemical irritation and inflammation [63]. Sensory neurons located within DRG are the first cells to receive afferent input from the pelvic viscera and, therefore, play a substantial role in the development of visceral sensitivity and pelvic discomfort during pathophysiological conditions. DRG neurons express several types of ion channels including TRPV1 and voltage-gated sodium channels (VGSC), both of which are well known transducers of nociceptive processing in pain pathways $[64,65]$. Experiments utilizing animal models of acute and chronic inflammation in the genitourinary tract showed an increased excitability of DRG neurons receiving direct input from the affected organs $[49,66,67]$. In this study, we determined that instillations of intravesical VEGF caused an up-regulation of VGSC in bladder sensory neurons identified by retrograde labeling. Overexpression of VGSC in bladder DRG cells is associated with increased neuronal excitability and enhanced firing rate [21]. Our results also support the data from human studies which suggested that abdominal pain and altered bladder and pelvic hypersensitivity in patients with $\mathrm{OAB}$ and PBS may involve organizational and/or functional changes in visceral afferent pathways when bladder sensory neurons become sensitized and hyper-responsive to normally innocuous stimuli such as bladder filling $[68,69]$.

Multiple sodium channel isoforms are expressed in DRG neurons [70]. Sodium channels play a central role in neuronal electrogenesis, therefore, variations in the level of expression of any one of the sodium channel isoforms could, in principle, alter their level of excitability [71]. However, a number of modulatory factors such as neuronal functional status, homeostatic regulation of ion channel expression, post-translational modifications, and interactions with regulating molecules and trophic factors can also significantly affect neuronal excitability [70]. For instance, brief exposure to NGF, interferon gamma, epidermal growth factor or basic fibroblast growth factor can induce an up-regulation of expression of $\mathrm{Na}_{\mathrm{v}} 1.7$ channel [72]. Interactions of $\mathrm{Na}^{+}$ channels with partner molecules including NGF [73,74], GDNF [73], contactin [75,76], annexin [77], gabapentin [78], and other modulators [79] were established to regulate expression of multiple sodium channel isoforms. Based on these observations, we suggest that the effects of VEGF treatment on $\mathrm{Na}^{+}$channels in our study could be associated either with the changes in the expression ratio between different $\mathrm{Na}^{+}$channel isoforms in bladder sensory neurons or modulation of $\mathrm{Na}^{+}$channel function by regulatory molecules as outlined above [70]. Additional studies are warranted to identify the exact mechanisms of VEGF action on specific $\mathrm{Na}^{+}$channels isoforms and electrical activity of bladder sensory neurons.

The results of behavioral experiments revealed, for the first time, that intravesical VEGF induced the development of abdominal hypersensitivity detected by mechanical stimulation of the lower pelvic region. These effects may be explained, in part, by the ability of VEGF to increase the density of SP and TRPV1 positive fibers [17]. This suggestion correlates with the previously published studies, which confirmed participation of TRPV1 in the development of abdominal hyperalgesia and neuropathic pain [80]. Results with TRPV1 knockout mice support the role of TRPV1 in mediating changes in sensitivity. Wang et al. determined that abdominal hyperreactivity and cutaneous allodynia were significantly diminished in these genetically modified animals although the lack of functional TRPV1 receptors did not improve the histological changes in the inflamed bladder induced by either cyclophosphamide (CYP) or acrolein [51]. In addition to the involvement of TRPV1 afferents in pelvic sensitivity, other receptors and molecules can also contribute to abdominal hyperalgesia depending on the model and nature of chosen inflammatory agents [81]. Thus, increased peripheral sensitivity in mice with bacterial cystitis was related to activation of toll-like receptor 4 [82]. In the acrolein model of bladder inflammation in rats, increased mechanical sensitivity was conveyed, in part, via NGF and trk receptors [83]. Likewise, inflammatory events experienced earlier in life were established to trigger long lasting changes in sensory pathways leading to altered pelvic sensations during the adulthood $[84,85]$. Altogether, our data provide direct evidence that VEGF-induced neurogenic inflammation in the urinary bladder is associated with significant structural and functional changes that may play a key role in the development of neurogenic bladder dysfunctions in humans.

\section{Conclusion}

The discovery that neuronal guidance molecules such as neuropilins function as co-receptors for VEGF has opened up a new field of VEGF research and has even revealed potentially new roles for VEGF in axonal growth [86]. In other words, sprouting of neuronal axons and vessels appear to use common molecular mechanisms for navigation based upon NRP-VEGF interactions [87].

We previously provided strong evidence indicating that the mouse [25] and human urothelium [31] express an extraordinary level of VEGF receptors and that the expression of these receptors is fundamentally altered in bladder biopsies of PBS patients [31]. Additional results supported the hypothesis that the mouse bladder urothelium actively internalizes VEGF [31].

Nevertheless, the function exerted by VEGF in the LUT is not clear. In both neuronal and vascular cells VEGF is known to increase permeability, prevent apoptosis [88], and promote cell survival [89] and proliferation [90]. Whether VEGF exhibits the same functions on urothelial 
cells remains to be determined. The results presented in this manuscript indicate that VEGF also participates in bladder neuronal plasticity and that the increased nerve density is accompanied by alterations in bladder function and visceral sensitivity.

\section{Methods}

\section{Animals and experimental groups}

All animal experimentation conformed to the APS's Guiding Principles in the Care and Use of Animals and was approved by the OUHSC Animal Care \& Use Committee (protocol \#08-105), University of Wisconsin-Madison (protocol M02497), and University of Pennsylvania School of Medicine (protocol \# 802979)

For the visualization of cholinergic neurons we used genetically engineered mice with an "IRES-Cre" sequence inserted downstream of the stop codon such that cre expression is controlled by the endogenous Chat gene

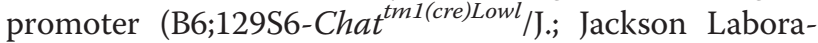
tories stock \# 006410). We mated the ChAT-cre mice with Rosa stop $t d$ tomato mice. The resulting offspring express the fluorescent protein (td tomato) in all cholinergic cells and fibers, as the cre deletes the stop signals flanking the $\mathrm{td}$ tomato sequence. In these mice, Chat gene expression, however, is unaffected. For simplicity, this mouse strain will be referred as ChAT mice.

Adult C57BL/6J and ChAT female mice (10-12 wks old, Jackson Laboratory) were used in this study and maintained on a 12-hour light/dark cycle with ad libitum access to water and food.

Intravesical instillation was described in [91]. Briefly, 2-4 month-old female mice were anesthetized with isoflurane (between 1 and $2.5 \%$ titrated to effect) and transurethrally catheterized with a polypropylene catheter (24 gauge; 3/4 in.; $19 \mathrm{~mm}$ long, inside diameter $0.47 \mathrm{~mm}$, outside diameter $0.67 \mathrm{~mm}$; Angiocath, Becton-Dickinson, Sandy, UT). Test compounds were instilled via a syringe attached to the catheter at a slow rate to avoid trauma and vesicoureteral reflux. $100 \mu \mathrm{l}$ of one of the following substances were instilled: pyrogen-free saline (PBS; controls) or mouse recombinant VEGF, also known as VEGF-A or VEGF $_{165}$ (6.41 nM in $100 \mu \mathrm{l}$; ProSpec-Tany TechnoGene Ltd [Rehovot 76124, Israel; catalog \# MGC70609]). To ensure consistent contact of substances with the bladder and to avoid reflux or leakage, the catheter was occluded and left in place for 30 minutes. Mice received one or twice weekly innstillation of VEGF, as described in the particular figure legend. The groups of mice were euthanized one week post-instillation, and the urinary bladders were removed and examined as whole mounts. Subsequently, the urinary bladders were sectioned and visualized as cross-sections and immunofluorescence was used for image analysis of cholinergic and sensory nerves.

\section{Functional Studies}

C57BL/6J female mice were randomly divided into three experimental groups: 1 - cystometry studies $(\mathrm{N}=5) ; 2$ control group for electrophysiological experiments (intravesical PBS, N=5); 3 - VEGF group (intravesical VEGF, $\mathrm{N}=5$ ). Animals in all groups first underwent survival surgeries as described below followed by 3 intravesical instillations of either PBS or vascular endothelial growth factor (VEGF, $100 \mu \mathrm{L}, 6.41 \mathrm{nM}$ in $100 \mu \mathrm{l}$, groups 1 and 3) within a 2 -week period (every $4^{\text {th }}$ day), see Table 1 .

\section{Bladder whole mounts}

Urinary bladders were isolated from ChAT mice, the urine was drained, and tissues were fixed in $4 \%$ paraformaldehyde for 4-6 hours at room temperature or overnight at $4^{\circ} \mathrm{C}$. After fixation, the tissue was washed in PBS twice and placed in 1\% triton X-100 for 4-6 hours at room temperature or overnight at $4{ }^{\circ} \mathrm{C}$. After the tissue was washed in PBS, the primary antibodies were added for 4-6 hours at room temperature or overnight at $4^{\circ} \mathrm{C}$, washed off in PBS, and the secondary antibodies were added for 4-6 hours at room temperature or overnight at $4^{\circ} \mathrm{C}$. Whole mounts were visualized and photographed with a dissecting fluorescence microscope (Nikon SMZ 1500 microscope equipped with high-resolution Plan 1.6 WD24 objective lenses). For detailed visualization of ChAT and TRPV1 nerves along with blood vessels, some of the whole mounts were blunt dissected to separate the urothelium together with the suburothelium/lamina propria [92] from the detrusor smooth muscle. Photomicrographs were taken with the lamina propria facing upward and the urothelium downward or the detrusor smooth muscle facing upward and the adventitia downward. Subsequently, tissues were frozen in 1:1 tissue freezing media (TFM, Triangle Biomed Sciences) and OCT (Tissue Tek ${ }^{\circledR}$ ) and sectioned with a cryostat. Cross-sections were examined by immunofluorescence, as described below.

\section{Immunofluorescence (IF) of mouse tissues}

Urinary bladders were processed for IF according to published methods [93]. For all tissues, appropriate crosssectional morphology was confirmed by H\&E staining and examination by light microscopy prior to preparing slides for IF labeling. Frozen sections $(10,15$, or $40 \mu \mathrm{m}$ thick, as indicated in the figure legend) were post-fixed in $1 \%$ $\mathrm{MeOH}$-free formaldehyde for all stains. Briefly, slides were blocked for 35 minutes with 5\% normal donkey serum (NDS; Jackson Immunolabs), then co-incubated with primary antibodies in $0.5 \%$ NDS for 90 minutes in a humidified chamber or overnight at $4^{\circ} \mathrm{C}$. When double IF was used, following brief rinses with PBS, slides were coincubated with both secondary antibodies at the same time. Controls included slides labeled only with individual primary or secondary antibodies. 
Table 1 Experimental scheme for functional studies

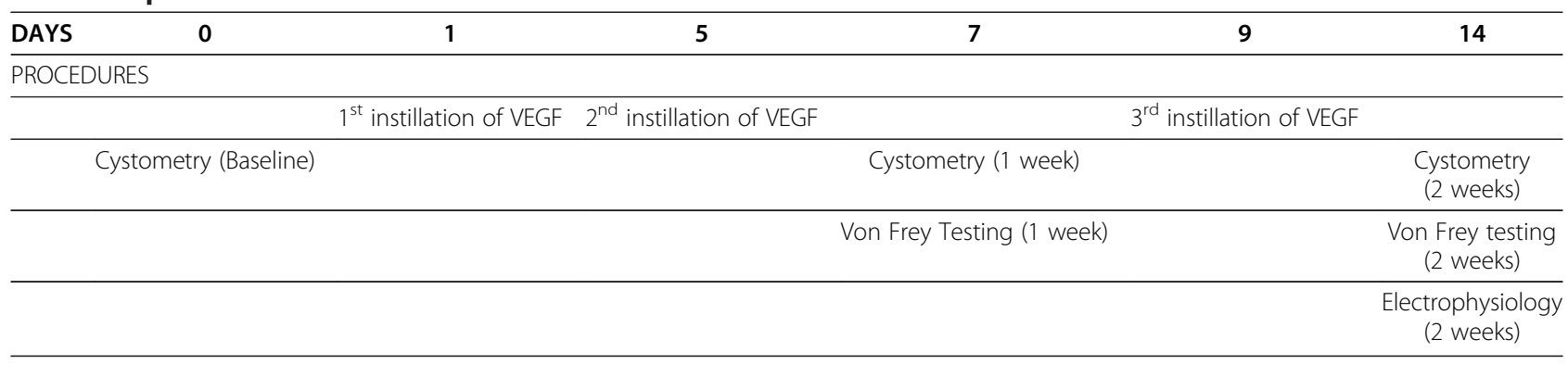

\section{Primary antibodies}

TRPV1 antibody $(1: 10,000)$ was raised in rabbits against the $15 \mathrm{C}$-terminal amino acids of the rat TRPV1 sequence [94]. Commercially available antibodies included: rabbit anti-human protein gene product 9.5 [PGP9.5] (Neuromics; catalog \# RB12103, 1:1500 dilution), rabbit anti-mouse substance P (Millipore; catalog AB1566; 1:250 dilution), guinea pig anti-rat substance P (Millipore; catalog AB15810; 1:1000 dilution), rat anti-mousederived endothelioma cell line [CD31] (BD Pharmingen; \#550274; 1:200), rabbit anti- $\beta$ III tubulin [TuJ1] (Gift from Dr. Anthony Frankfurter; 1:250).

\section{Secondary antibodies}

All secondary antibodies were used at a 1:500 dilution and included donkey anti-rabbit IgG Alexafluor 488 and 546 conjugate (Molecular Probes), donkey anti-goat IgG Alexafluor 546, donkey anti-rat IgG Alexafluor 488, goat anti-guinea pig 546 ,donkey anti-rat Cy5 (Jackson ImmunoResearch), donkey anti-rabbit Dylight 488), donkey anti-rabbit Cy5. Slides were washed, counterstained with 4, 6-diamidino-2-phenylindole (DAPI), and coverslipped.

\section{Image analysis}

A Nikon A1R scanning confocal microscope (Melville, NY) controlled by NIS-Elements C (Nikon) was used to image whole mounts and cross sections at UW-Madison. For image analysis, all tissue cross-sections were viewed with a Nikon Eclipse TE 2000-S inverted fluorescent microscope at OUHSC and imaged at room temperature using a digital CCD camera (Roper Scientific; Sarasota, Florida 34240) driven by NIS-Elements AR 3.0 Imaging software. A control slide stained only with secondary antibody was used to determine exposure time and to set minimum background fluorescence levels for each fluorophore imaged. Once set, exposure times were not changed during acquisition of each respective fluorophore in the staining series. Staining was considered positive only when the acquired signal exceeded the established background. Absence of signal bleed-through was determined using previously optimized multi-acquisition settings on single fluorophore stained slides. DAPI staining was viewed using a DAPI filter set (340-380nm ex, 435-485nm em). Imaging of Alexafluor 488 utilized an excitation filter of 465-495nm and an emission filter of 515-555nm. Alexafluor 546 was imaged with an excitation of 528-553nm and 590-650nm emission range.

\section{Quantification of nerve fibers}

Histologically nerve fibers undulate in and out of the plane of the section, sometimes appearing as linear structures, and sometimes as punctate staining, indicating presumed nerves in cross-section. Therefore, the following parameters were used in order to exclude structures above or below a certain size as being potentially non-neuronal and to exclude inflammatory cells since monocytes and macrophages have been reported to express TRPV1 [95]. In this context, for image analysis of nerves, the NISElements AR 3.0 Imaging software was set to count only structures with length between 0.19-500 $\mu \mathrm{m}$ and width 0.19-2.5 $\mu \mathrm{m}$. [Length is a derived feature appropriate for elongated or thin structures. Length $=($ Perimeter + sqrt (Perimeter ${ }^{2}-16^{*}$ Area) $\left.) / 4\right]$; and Width is a derived feature appropriate for elongated or thin structures. It is based on the rod model and is calculated according to the following formula: Width = Area/Length].

To meet the independent randomized sampling assumption required for our statistical test(s), the following measures were taken: blinding the reader to treatment groups and picking a random starting position and proceeding clockwise with 6-10 non-overlapping images. As 12-20 fields are necessary to view the whole bladder cross-section at 400X magnification, the sampling of 6-10 non-overlapping images represented half of the entire bladder cross-section. The area occupied by cells stained positively with td tomato or TRPV1 antibody was calculated as percent of the total area of the region of interest (ROI), as indicated in the individual figure legend and the results of 6-10 fields were averaged. This procedure was repeated for all bladders used per treatment group and the results are expressed as mean \pm SEM of cross-sections. The data were examined to determine if the distributions were homoscedastic and Gaussian. As these conditions 
were met, groups were compared through a two-sample Student's t test. An alpha of 0.05 was considered statistically significant. $P$-values were adjusted for multiple comparisons through a Bonferroni correction.

\section{Surgical procedure to catheterize the urinary bladder in mice}

Mice included in the group for urodynamic evaluation of the urinary bladder function (awake cystometry) underwent the following survival surgical procedure to insert bladder catheters. An animal was anesthetized with isoflurane (VEDCO, St. Joseph, MO), and a PTF catheter with a blunted end (Catamount Research, St. Albans, VT) was sutured in place at the bladder dome and tunneled out the abdomen to the nape of the neck where it was then inserted into the end of a 22-gauge angiocath iv catheter. Upon determination of the optimal length, the PTF catheter was affixed to the angiocath with super glue. The angiocath was first tested with a gentle saline infusion to reveal no leak at the bladder, and then capped and the abdomen was closed in layers. The angiocath was anchored to the fascia and skin of the neck using two to three 3-0 Vicryl sutures. Animals were kept in individual cages to avoid possible damage to the catheters by their cage mates. Mice were allowed to recover from surgery for 4 days followed by cystometric evaluation of bladder function under normal conditions (baseline cystometry). After initial urodynamic evaluation mice received 3 intravesical instillations of VEGF as described above.

\section{Surgical procedure for labeling urinary bladder DRG neurons}

Mice were anaesthetized with $2 \%$ isoflurane and held on a warming pad inside a fume hood to minimize the investigator's exposure to the anesthetic. A midline laparotomy was performed under sterile conditions to gain access to the urinary bladder. Urinary bladder was exposed and Fast Blue (Polysciences Inc., Warrington, PA, USA; 1.5\% w/v in water) was injected into the urinary bladder wall (detrusor at 6 - 10 sites) using a Hamilton syringe with 26-gauge needle. The total volume of dye injected into the bladder was 20-25 $\mu$ l. Adjacent pelvic organs were isolated with gauze to soak up any spills and prevent the labeling of adjacent structures during injections. Additionally, the needle was kept in place for 30 minutes after each injection. Any leaked dye was removed with a cotton swab before placing the organ into the pelvic cavity. Incisions were sutured in layers under sterile conditions followed by subcutaneous injection of buprenorphine $(0.5 \mathrm{mg} / \mathrm{kg})$. Animals were allowed to recover on a warm blanket until they gained full consciousness and then were returned to their cages. Mice started treatments with intravesical VEGF (or PBS in the control group) 10 days after labeling of bladder sensory neurons.

\section{Urodynamic evaluation of bladder function}

Conscious mice were placed in cystometry cages $(16 \mathrm{~cm}$ width, $12 \mathrm{~cm}$ height, and $24 \mathrm{~cm}$ length) without any restraint and allowed to acclimate for $30 \mathrm{~min}$. The tip of the exteriorized bladder catheter located at the base of the mouse neck was connected to a pressure transducer and an infusion pump of the cystometry station (Small Animal Laboratory Cystometry, Catamount Research and Development, St. Albans, VT) using a T-shaped valve. Room temperature saline solution $(0.9 \% \mathrm{NaCl})$ was infused into the bladder at a rate of $10 \mu \mathrm{l} / \mathrm{min}$. Voided urine was collected in the tray connected to a force displacement transducer integrated into the data acquisition system. Each animal was observed for up to six-eight voiding cycles. Urodynamic values were recorded continuously using data acquisition software (Small Animal Laboratory Cystometry, Catamount Research and Development). The following cystometric parameters were recorded and analyzed in this study: bladder capacity, pressure at the start of micturition, micturition rate, continuous intravesicular pressure, intermicturition interval, and the number of non-micturition contractions. Non-micturition contractions were defined as increased values in detrusor pressure from the baseline that had amplitudes of at least a third of maximal pressure at the start of micturition. Each animal underwent baseline cystometric evaluation followed by intravesical instillations of VEGF. The second cystometric assessment was done after two VEGF instillations (1 week after the first dose) and the third cystometry was performed 3 days after completion of all three VEGF treatments at 2 weeks after the baseline measurement (day 0), Table 1.

Cystometric parameters were uploaded from the acquisition software into analysis software (SOF-552 Cystometry Data Analysis, Version 1.4, Catamount Research and Development Inc., St. Albans, Vermont). Maximum pressure at micturition, bladder capacity, micturition volume, number of non-micturition contractions, intermicturition interval and micturition rate indices were calculated. All data are expressed as the mean \pm standard error of the mean (S.E.M). The results were statistically analyzed using one-way repeated measures ANOVA between baseline and 2 urodynamic assessments followed by Bonferroni`s post test, as appropriate (Systat Software Inc., San Jose, $\mathrm{CA})$. A difference in values between the baseline and treatments was considered statistically significant at $\mathrm{p} \leq 0.05$.

\section{Isolation of bladder DRG neurons for patch-clamp experiments}

Animals were euthanized by overdose of sodium pentobarbital $(130 \mathrm{mg} / \mathrm{kg}) 2$ weeks after the beginning of VEGF treatments. Dorsal root ganglia were dissected and removed bilaterally at L6-S2 levels. The ganglia were treated with collagenase (Worthington, type 2, Biochemical Corp., Lakewood, NJ, USA) in F-12 medium (Invitrogen, 
Carlsbad, CA, USA) for $90 \mathrm{~min}$ in an incubator with $95 \%$ $\mathrm{O}_{2}$ and $5 \% \mathrm{CO}_{2}$ at $37^{\circ} \mathrm{C}$. Isolated ganglia were then rinsed in phosphate-buffered saline (PBS) and incubated for 15 min in the presence of trypsin (Sigma, St Louis, MO, USA; $1 \mathrm{mg} / \mathrm{ml}$ ) at room temperature. The enzymatic reaction was terminated in Dulbecco's Modified Eagle's Medium (DMEM) containing 10\% of fetal bovine serum (FBS). Single neurons were obtained by gentle trituration using fire-polished Pasteur pipettes in DMEM with trypsin inhibitor (Sigma; $2 \mathrm{mg} / \mathrm{ml}$ ) and deoxyribonuclease (Sigma; DNase $1 \mathrm{mg} / \mathrm{ml}$ ). The cell suspension was centrifuged for $10 \mathrm{~min}$ at $700 \mathrm{rpm}\left(4^{\circ} \mathrm{C}\right)$, and supernatant was discarded. The pellet, containing sensory neurons, was resuspended in $2 \mathrm{ml}$ of DMEM containing $10 \%$ FBS. Neurons were plated on poly-L-ornithine coated $35 \mathrm{~mm}$ Petri dishes. Isolated cells were maintained overnight in an incubator at $37^{\circ} \mathrm{C}$ with $95 \% \mathrm{O}_{2} / 5 \% \mathrm{CO}_{2}$ and were used for electrophysiological experiments within 24 hours.

\section{Electrophysiological recordings of voltage gated $\mathrm{Na}^{+}$ currents from bladder dorsal root ganglion neurons}

Bladder labeled neurons were identified with an inverted fluorescent microscope (Ti E2000-5, Nikon containing a specific filter for Fast Blue (UV-2A, Nikon). Only neurons exhibiting bright blue fluorescence (Fast Blue labeled) were used for $\mathrm{Na}^{+}$current recordings using the whole-cell patch clamp technique. For voltage clamp experiments the external solution contained (in $\mathrm{mM}$ ): $\mathrm{NaCl} 45$, TEA Chloride 30, Choline Chloride 60, $\mathrm{KCl} 5.4, \mathrm{MgCl}_{2} 1, \mathrm{CaCl}_{2}$ 1, HEPES 5, D-glucose 5.5, adjusted with $\mathrm{NaOH}$ to $\mathrm{pH}$ 7.4. Pipette solution for these experiments consisted of (in $\mathrm{mM}$ ): L-aspartic acid 100, $\mathrm{CsCl} 30, \mathrm{MgCl}_{2}$ 2, Na-ATP 5, EGTA 5, HEPES 5 adjusted with $\mathrm{CsOH}$ to $\mathrm{pH} \mathrm{7.2.} \mathrm{CdCl}$ $(100 \mu \mathrm{M})$ was added to the external solution in order to block voltage gated calcium currents. Freshly made Amphotericin B $(0.24 \mathrm{mg} / \mathrm{ml}$, ACROS, NJ, USA) was added to the pipette solution for perforated whole cell recordings. Microelectrodes were fabricated from borosilicate capillary glass (Sutter instruments, Novato, CA) and had resistances of 2-5 $\mathrm{M} \Omega$ when filled with internal solution. Recordings commenced $5 \mathrm{~min}$ after the establishment of whole cell access. Series resistance was compensated $\geq 80-85 \%$, and the calculated junction potential was around $5 \mathrm{mV}$. Cells were excluded from analysis if uncompensated series resistance resulted in a maximum voltage error $>5 \mathrm{mV}$ or if the seal or access resistance were unstable. Recordings and analysis of kinetic parameters of voltage gated $\mathrm{Na}^{+}$channels were performed using previously established protocols [9].

pCLAMP software (Axon Instruments, CA) was used for data acquisition and analysis. All data are expressed as means \pm SEM. Statistical significance between the groups was assessed by one-way ANOVA followed by
Bonferroni`s test. Data with $\mathrm{p} \leq 0.05$ were considered statistically significant.

\section{Assessment of visceral sensitivity using von Frey filaments}

Mice were tested before and after intravesical instillations of VEGF. Irritation and/or inflammation in the pelvic viscera are associated with enhanced abdominal sensitivity due to convergence of visceral and somatic inputs on the second order neurons in the dorsal horn of the spinal cord [21]. This phenomenon is known as viscerosomatic (called hyperalgesia) and is measured by using mechanical stimulation with von Frey filaments on the lower abdominal/ pelvic area. Mice were tested in individual Plexiglas chambers $(6 \times 10 \times 12 \mathrm{~cm})$ with a stainless steel wire grid floor (mouse acclimation period was $30 \mathrm{~min}$ before testing). Frequency of withdrawal responses was tested using five individual fibers with forces of $0.04,0.16,0.4,1$, and $4 \mathrm{~g}$ (Stoelting). Each filament was applied for 1-2 s with an interstimulus interval of $5 \mathrm{~s}$ for a total of 10 times, and the hairs were tested in ascending order of force. Stimulation was confined to the lower abdominal area in the general vicinity of the bladder, and care was taken to stimulate different areas within this region to avoid desensitization or "wind up" effects. Three types of behavior were considered as positive responses to filament stimulation: 1) sharp retraction of the abdomen, 2) immediate licking or scratching of the area of filament stimulation, or 3) jumping as previously described [96].

\section{Authors' contributions}

This manuscript reports the results of studies developed at the University of Pennsylvania (UP), UW-Madison, and OUHSC. At the UW-Madison, under the directions of MLE, MRS anesthetized and instilled the ChAT mice and CSE developed the analysis of bladder whole mounts and immunofluorescence of mouse tissues. At the OUHSC, under the direction of MRS, CAD developed image analysis and quantification of nerve fibers. At the UP, under the direction of APM, QL developed the functional studies, including urodynamic evaluation of bladder function, isolation of bladder DRG neurons for patchclamp experiments, electrophysiological recordings of voltage gated $\mathrm{Na}^{+}$ currents from bladder dorsal root ganglion neurons, and assessment of visceral sensitivity using von Frey filaments. RS conceived the study, analyzed the results, and prepared the manuscript. All authors read and approved the final manuscript.

\section{Acknowledgements}

This research was supported by the Department of Defense Medical Research Program (PRMRP) under award number PR080981 (RS). Views and opinions of, and endorsements by the author(s) do not reflect those of the US Army or the Department of Defense. Studies at UW-Madison were supported by R01-DK081634 (MLE). Studies at UP were supported by DK077699 (APM).

\section{Author details}

'Department of Surgery, Division of Urology, University of Pennsylvania School of Medicine, Glenolden, PA 19036-2307, USA. 'Department of Neurosciences, University of Wisconsin-Madison, Madison, WI 53706, USA. ${ }^{3}$ Department of Physiology, College of Medicine, Urinary Tract Physiological Genomics Laboratory, University of Oklahoma Health Sciences Center (OUHSC), 800 Research Parkway, Room 410, Oklahoma City, OK 73104, USA. 
Received: 3 October 2012 Accepted: 11 December 2012

Published: 19 December 2012

\section{References}

1. Avelino A, Cruz F: TRPV1 (vanilloid receptor) in the urinary tract: expression, function and clinical applications. Naunyn Schmiedebergs Arch Pharmacol 2006, 373(4):287-299.

2. Andersson KE, Hedlund P: Pharmacologic perspective on the physiology of the lower urinary tract. Urology 2002, 60(5 Suppl 1):13-20. discussion 20-11.

3. Ford AP, Cockayne DA: ATP and P2X purinoceptors in urinary tract disorders. Handb Exp Pharmacol 2011, 202:485-526.

4. Asfaw TS, Hypolite J, Northington GM, Arya LA, Wein AJ, Malykhina AP Acute colonic inflammation triggers detrusor instability via activation of TRPV1 receptors in a rat model of pelvic organ cross-sensitization. Am J Physiol Regul Integr Comp Physiol 2011, 300(6):R1392-R1400.

5. Saban R, Saban MR, Nguyen NB, Lu B, Gerard C, Gerard NP, Hammond TG: Neurokinin-1 (NK-1) receptor is required in antigen-induced cystitis. Am J Pathol 2000, 156(3):775-780.

6. Saban R, D'Andrea MR, Andrade-Gordon P, Derian CK, Dozmorov I, Ihnat MA, Hurst RE, Davis CA, Simpson C, Saban MR: Mandatory role of proteinase-activated receptor 1 in experimental bladder inflammation. BMC Physiol 2007, 7:4.

7. Schnegelsberg B, Sun TT, Cain G, Bhattacharya A, Nunn PA, Ford AP, Vizzard MA, Cockayne DA: Overexpression of NGF in mouse urothelium leads to neuronal hyperinnervation, pelvic sensitivity, and changes in urinary bladder function. Am J Physiol Regul Integr Comp Physiol 2010, 298(3):R534-R547.

8. Alagiri M, Chottiner S, Ratner V, Slade D, Hanno PM: Interstitial cystitis: unexplained associations with other chronic disease and pain syndromes. Urology 1997, 49(5A Suppl):52-57.

9. Lei Q, Malykhina AP: Colonic inflammation up-regulates voltage-gated sodium channels in bladder sensory neurons via activation of peripheral transient potential vanilloid 1 receptors. Neurogastroenterol Motil 2012, 24(6):575-585. e257.

10. Martin P, Lewis J: Origins of the neurovascular bundle: interactions between developing nerves and blood vessels in embryonic chick skin. Int J Dev Biol 1989, 33(3):379-387.

11. Carmeliet $P$, Tessier-Lavigne $M$ : Common mechanisms of nerve and blood vessel wiring. Nature 2005, 436(7048):193-200.

12. Mukouyama YS, Shin D, Britsch S, Taniguchi M, Anderson DJ: Sensory nerves determine the pattern of arterial differentiation and blood vessel branching in the skin. Cell 2002, 109(6):693-705.

13. Yuan L, Moyon D, Pardanaud L, Breant C, Karkkainen MJ, Alitalo K, Eichmann A: Abnormal lymphatic vessel development in neuropilin 2 mutant mice. Development 2002, 129(20):4797-4806.

14. de Almodovar Ruiz C, Lambrechts D, Mazzone M, Carmeliet P: Role and therapeutic potential of VEGF in the nervous system. Physiol Rev 2009, 89(2):607-648

15. Charrua A, Reguenga C, Cordeiro JM, Correiade-Sa P, Paule C, Nagy I, Cruz F, Avelino A: Functional transient receptor potential vanilloid 1 is expressed in human urothelial cells. J Urol 2009, 182(6):2944-2950.

16. Doran JF, Jackson P, Kynoch PA, Thompson RJ: Isolation of PGP 9.5, a new human neurone-specific protein detected by high-resolution two-dimensional electrophoresis. J Neurochem 1983, 40(6):1542-1547.

17. Saban MR, Davis CA, Avelino A, Cruz F, Maier J, Bjorling DE, Sferra TJ, Hurst RE, Saban R: VEGF signaling mediates bladder neuroplasticity and inflammation in response to BCG. BMC Physiol 2011, 11:16.

18. Carmeliet $P$ : Neuro-vascular link: from genetic insights to therapeutic perspectives. Bull Mem Acad R Med Belg 2008, 163(10-12):445-451. discussion 451-442

19. Avwenagha O, Campbell G, Bird MM: Distribution of GAP-43, beta-III tubulin and F-actin in developing and regenerating axons and their growth cones in vitro, following neurotrophin treatment. J Neurocytol 2003, 32(9):1077-1089.

20. Birder LA, Wolf-Johnston AS, Sun Y, Chai TC: Alteration in TRPV1 and Muscarinic (M3) receptor expression and function in idiopathic overactive bladder urothelial cells. Acta Physiol (Oxf) 2013, 207(1):123-129.

21. Ritter AM, Martin WJ, Thorneloe KS: The voltage-gated sodium channel Nav1.9 is required for inflammation-based urinary bladder dysfunction. Neurosci Lett 2009, 452(1):28-32.
22. Carmeliet P: Blood vessels and nerves: common signals, pathways and diseases. Nat Rev Genet 2003, 4(9):710-720.

23. Kuruvilla R, Zweifel LS, Glebova NO, Lonze BE, Valdez G, Ye H, Ginty DD: A neurotrophin signaling cascade coordinates sympathetic neuron development through differential control of TrkA trafficking and retrograde signaling. Cell 2004, 118(2):243-255.

24. Tamaki M, Saito R, Ogawa O, Yoshimura N, Ueda T: Possible mechanisms inducing glomerulations in interstitial cystitis: relationship between endoscopic findings and expression of angiogenic growth factors. J Urol 2004, 172(3):945-948.

25. Saban MR, Backer JM, Backer MV, Maier J, Fowler B, Davis CA, Simpson C, Wu X-R, Birder L, Freeman MR, Soker S, Saban R: VEGF receptors and neuropilins are expressed in the urothelial and neuronal cells in normal mouse urinary bladder and are up-regulated in inflammation Am J Physiol Renal 2008, 295. doi:10.1152/ajprenal.00618.02007.

26. Saban R, Saban MR, Maier J, Fowler B, Tengowski M, Davis CA, Wu XR, Culkin DJ, Hauser P, Backer J, Hurst RE: Urothelial expression of neuropilins and VEGF receptors in control and interstitial cystitis patients. Am J Physiol Renal Physiol 2008, 295(6):F1613-F1623.

27. Lee $S$, Chen TT, Barber CL, Jordan MC, Murdock J, Desai S, Ferrara N, Nagy A, Roos KP, Iruela-Arispe ML: Autocrine VEGF signaling is required for vascular homeostasis. Cell 2007, 130(4):691-703.

28. Sugimoto H, Hamano Y, Charytan D, Cosgrove D, Kieran M, Sudhakar A, Kalluri R: Neutralization of circulating vascular endothelial growth factor (VEGF) by anti-VEGF antibodies and soluble VEGF receptor 1 (sFlt-1) induces proteinuria. J Biol Chem 2003, 278(15):12605-12608.

29. Saban MR, Sferra TJ, Davis CA, Simpson C, Allen A, Maier J, Fowler B, Knowlton N, Birder L, Wu XR, Saban R: Neuropilin-VEGF signaling pathway acts as a key modulator of vascular, lymphatic, and inflammatory cell responses of the bladder to intravesical BCG treatment. Am J Physiol Renal Physiol 2010, 299(6):F1245-F1256.

30. Backer MV, Levashova Z, Patel V, Jehning BT, Claffey K, Blankenberg FG, Backer JM: Molecular imaging of VEGF receptors in angiogenic vasculature with single-chain VEGF based probes. Nat Med 2007, 13(4):504-509.

31. Saban R, Saban MR, Maier J, Fowler B, Tengowski M, Davis CA, Wu XR Culkin DJ, Hauser P, Backer J, Hurst RE: Urothelial expression of neuropilins and VEGF receptors in control and interstitial cystitis patients. PMID: 18815217 American journal of physiology. Ren Physiol 2008, 295(6):F1613-F1623.

32. Saban MR, Backer JM, Backer MV, Maier J, Fowler B, Davis CA, Simpson C, Wu XR, Birder L, Freeman MR, Soker S, Hurst RE, Saban R: VEGF receptors and neuropilins are expressed in the urothelial and neuronal cells in normal mouse urinary bladder and are upregulated in inflammation. Am J Physiol Renal Physiol 2008, 295(1):F60-F72.

33. Schmitt $M$, Horbach A, Kubitz R, Frilling A, Haussinger D: Disruption of hepatocellular tight junctions by vascular endothelial growth factor (VEGF): a novel mechanism for tumor invasion. $J$ Hepatol 2004, 41(2):274-283

34. Rodewald M, Herr D, Fraser HM, Hack G, Kreienberg R, Wulff C: Regulation of tight junction proteins occludin and claudin 5 in the primate ovary during the ovulatory cycle and after inhibition of vascular endothelial growth factor. Mol Hum Reprod 2007, 13(11):781-789.

35. Nico B, Mangieri D, Crivellato E, Longo V, De Giorgis M, Capobianco C, Corsi P, Benagiano V, Roncali L, Ribatti D: HIF activation and VEGF overexpression are coupled with ZO-1 up-phosphorylation in the brain of dystrophic mdx mouse. Brain Pathol 2007, 17(4):399-406.

36. Acharya P, Beckel J, Ruiz WG, Wang E, Rojas R, Birder L, Apodaca G: Distribution of the tight junction proteins ZO-1, occludin, and claudin-4, -8 , and -12 in bladder epithelium. Am J Physiol Renal Physiol 2004, 287(2):F305-F318.

37. Saban MR, Sferra TJ, Davis CA, Simpson C, Allen A, Maier J, Fowler B, Knowlton N, Birder L, Wu XR, Saban R: Neuropilin-VEGF signaling pathway acts as a key modulator of vascular, lymphatic, and inflammatory cell responses of the bladder to intravesical BCG treatment. PMID: 20861073. Am J Physiol Renal Physiol 2010, 299(6):F1245-F1256.

38. Silva C, Avelino A, Souto-Moura C, Cruz F: A light- and electron-microscopic histopathological study of human bladder mucosa after intravesical resiniferatoxin application. BJU Int 2001, 88(4):355-360.

39. Brockington A, Wharton SB, Fernando M, Gelsthorpe $C H$, Baxter L, Ince PG, Lewis CE, Shaw PJ: Expression of vascular endothelial growth factor and 
its receptors in the central nervous system in amyotrophic lateral sclerosis. J Neuropathol Exp Neurol 2006, 65(1):26-36.

40. Ogunshola OO, Antic A, Donoghue MJ, Fan SY, Kim H, Stewart WB, Madri JA, Ment LR: Paracrine and autocrine functions of neuronal vascular endothelial growth factor (VEGF) in the central nervous system. J Biol Chem 2002, 277(13):11410-11415.

41. Damon DH: Vascular endothelial-derived semaphorin 3 inhibits sympathetic axon growth. Am J Physiol Heart Circ Physiol 2006, 290(3):H1220-H1225.

42. Marko SB, Damon DH: VEGF promotes vascular sympathetic innervation. Am J Physiol Heart Circ Physiol 2008, 294(6):H2646-H2652.

43. Freeman MR, Schneck FX, Gagnon ML, Corless C, Soker S, Niknejad K, Peoples GE, Klagsbrun M: Peripheral blood T lymphocytes and lymphocytes infiltrating human cancers express vascular endothelial growth factor: a potential role for T cells in angiogenesis. Cancer Res 1995, 55(18):4140-4145.

44. Tracey KJ: The inflammatory reflex. Nature 2002, 420(6917):853-859.

45. Andersson $U$, Tracey KJ: Neural reflexes in inflammation and immunity. J Exp Med 2012, 209:1057-1068.

46. Burgu B, Medina Ortiz WE, Pitera JE, Woolf AS, Wilcox DT: Vascular endothelial growth factor mediates hypoxic stimulated embryonic bladder growth in organ culture. J Urol 2007, 177(4):1552-1557.

47. Christmas TJ, Rode J, Chapple CR, Milroy EJ, Turner-Warwick RT: Nerve fibre proliferation in interstitial cystitis. Virchows Arch A Pathol Anat Histopathol 1990, 416(5):447-451.

48. Lundeberg $T$, Liedberg $H$, Nordling $L$, Theodorsson E, Owzarski A, Ekman P: Interstitial cystitis: correlation with nerve fibres, mast cells and histamine. Br J Urol 1993, 71(4):427-429.

49. Charrua A, Cruz CD, Cruz F, Avelino A: Transient receptor potential vanilloid subfamily 1 is essential for the generation of noxious bladder input and bladder overactivity in cystitis. J Urol 2007, 177(4):1537-1541.

50. Dinis P, Charrua A, Avelino A, Yaqoob M, Bevan S, Nagy I, Cruz F: Anandamide-evoked activation of vanilloid receptor 1 contributes to the development of bladder hyperreflexia and nociceptive transmission to spinal dorsal horn neurons in cystitis. J Neurosci 2004 24(50):11253-11263.

51. Wang ZY, Wang P, Merriam FV, Bjorling DE: Lack of TRPV1 inhibits cystitis-induced increased mechanical sensitivity in mice. Pain 2008, 139(1):158-167.

52. Girard BM, Tompkins JD, Parsons RL, May V, Vizzard MA: Effects of CYP-induced cystitis on PACAP/VIP and receptor expression in micturition pathways and bladder function in mice with overexpression of NGF in urothelium. J Mol Neurosci 2012, 48(3):730-743.

53. Merrill L, Girard BM, May V, Vizzard MA: Transcriptional and translational plasticity in rodent urinary bladder TRP channels with urinary bladder inflammation, bladder dysfunction, or postnatal maturation. J Mol Neurosci 2012, 48(3):744-756.

54. Lin G, Chen KC, Hsieh PS, Yeh CH, Lue TF, Lin CS: Neurotrophic effects of vascular endothelial growth factor and neurotrophins on cultured major pelvic ganglia. BJU Int 2003, 92(6):631-635.

55. Lin G, Shindel AW, Fandel TM, Bella AJ, Lin CS, Lue TF: Neurotrophic effects of brain-derived neurotrophic factor and vascular endothelial growth factor in major pelvic ganglia of young and aged rats. BJU Int 2010, 105(1):114-120.

56. Stewart AL, Anderson RB, Kobayashi K, Young HM: Effects of NGF, NT-3 and GDNF family members on neurite outgrowth and migration from pelvic ganglia from embryonic and newborn mice. BMC Dev Biol 2008, 8:73.

57. Pereira Lopes FR, Lisboa BC, Frattini F, Almeida FM, Tomaz MA, Matsumoto PK, Langone F, Lora S, Melo PA, Borojevic R, Han SW, Martinez AM: Enhancement of sciatic nerve regeneration after vascular endothelial growth factor (VEGF) gene therapy. Neuropathol Appl Neurobiol 2011, 37(6):600-612.

58. Nico B, Mangieri D, Benagiano V, Crivellato E, Ribatti D: Nerve growth factor as an angiogenic factor. Microvasc Res 2008, 75(2):135-141.

59. Fan BS, Lou JY: Enhancement of angiogenic effect of co-transfection human NGF and VEGF genes in rat bone marrow mesenchymal stem cells. Gene 2011, 485(2):167-171.
60. Saygili E, Pekassa M, Saygili E, Rackauskas G, Hommes D, Noor-Ebad F, Gemein C, Zink MD, Schwinger RH, Weis J, Marx N, Schauerte P, Rana OR: Mechanical stretch of sympathetic neurons induces VEGF expression via a NGF and CNTF signaling pathway. Biochem Biophys Res Commun 2011, 410(1):62-67.

61. Cesca F, Yabe A, Spencer-Dene B, Scholz-Starke J, Medrihan L, Maden CH, Gerhardt H, Orriss IR, Baldelli P, Al-Qatari M, Koltzenburg M, Adams RH, Benfenati F, Schiavo G: Kidins220/ARMS mediates the integration of the neurotrophin and VEGF pathways in the vascular and nervous systems. Cell Death Differ 2012, 19(2):194-208.

62. Neubrand VE, Cesca F, Benfenati F, Schiavo G: Kidins220/ARMS as a functional mediator of multiple receptor signalling pathways. J Cell Sci 2012, 125(Pt 8):1845-1854.

63. Sun $B, L i$ Q, Dong L, Rong W: lon channel and receptor mechanisms of bladder afferent nerve sensitivity. Auton Neurosci 2010, 153(1-2):26-32.

64. Caterina MJ: Vanilloid receptors take a TRP beyond the sensory afferent Pain 2003, 105(1-2):5-9.

65. Dib-Hajj SD, Cummins TR, Black JA, Waxman SG: Sodium channels in normal and pathological pain. Annu Rev Neurosci 2010, 33:325-347.

66. Cheng Y, Keast JR: Effects of estrogens and bladder inflammation on mitogen-activated protein kinases in lumbosacral dorsal root ganglia from adult female rats. BMC Neurosci 2009, 10:156.

67. Yu SJ, Xia CM, Kay JC, Qiao LY: Activation of extracellular signal-regulated protein kinase 5 is essential for cystitis- and nerve growth factor-induced calcitonin gene-related peptide expression in sensory neurons. Mol Pain 2012, 8(1):48.

68. Driscoll A, Teichman JM: How do patients with interstitial cystitis present? J Urol 2001, 166(6):2118-2120.

69. Yamaguchi O, Honda K, Nomiya M, Shishido K, Kakizaki H, Tanaka H, Yamanishi T, Homma Y, Takeda M, Araki I, Obara K, Nishizawa O, Igawa Y, Goto M, Yokoyama O, Seki N, Takei M, Yoshida M: Defining overactive bladder as hypersensitivity. Neurourol Urodyn 2007, 26(6 Suppl):904-907.

70. Rush AM, Cummins TR, Waxman SG: Multiple sodium channels and their roles in electrogenesis within dorsal root ganglion neurons. J Physiol 2007, 579(Pt 1):1-14

71. Waxman SG: Sodium channels, the electrogenisome and the electrogenistat: lessons and questions from the clinic. J Physio/ 2012, 590(Pt 11):2601-2612.

72. Toledo-Aral JJ, Brehm P, Halegoua S, Mandel G: A single pulse of nerve growth factor triggers long-term neuronal excitability through sodium channel gene induction. Neuron 1995, 14(3):607-611.

73. Leffler A, Cummins TR, Dib-Hajj SD, Hormuzdiar WN, Black JA, Waxman SG: GDNF and NGF reverse changes in repriming of $T$ X-sensitive $\mathrm{Na}(+)$ currents following axotomy of dorsal root ganglion neurons. J Neurophysiol 2002, 88(2):650-658.

74. Dib-Hajj SD, Black JA, Cummins TR, Kenney AM, Kocsis JD, Waxman SG: Rescue of alpha-SNS sodium channel expression in small dorsal root ganglion neurons after axotomy by nerve growth factor in vivo. J Neurophysiol 1998, 79(5):2668-2676.

75. Liu CJ, Dib-Hajj SD, Black JA, Greenwood J, Lian Z, Waxman SG: Direct interaction with contactin targets voltage-gated sodium channel $\mathrm{Na}(\mathrm{v})$ 1.9/NaN to the cell membrane. J Biol Chem 2001, 276(49):46553-46561.

76. Rush AM, Craner MJ, Kageyama T, Dib-Hajj SD, Waxman SG, Ranscht B: Contactin regulates the current density and axonal expression of tetrodotoxin-resistant but not tetrodotoxin-sensitive sodium channels in DRG neurons. Eur J Neurosci 2005, 22(1):39-49.

77. Okuse K, Malik-Hall M, Baker MD, Poon WY, Kong H, Chao MV, Wood JN: Annexin II light chain regulates sensory neuron-specific sodium channel expression. Nature 2002, 417(6889):653-656.

78. Yang RH, Wang WT, Chen JY, Xie RG, Hu SJ: Gabapentin selectively reduces persistent sodium current in injured type-a dorsal root ganglion neurons. Pain 2009, 143(1-2):48-55.

79. Wang W, Gu J, Li YQ, Tao YX: Are voltage-gated sodium channels on the dorsal root ganglion involved in the development of neuropathic pain? Mol Pain 2011, 7:16.

80. Toth DM, Szoke E, Bolcskei K, Kvell K, Bender B, Bosze Z, Szolcsanyi J, Sandor $Z$ : Nociception, neurogenic inflammation and thermoregulation in TRPV1 knockdown transgenic mice. Cell Mol Life Sci 2011, 68(15):2589-2601. 
81. Dupont MC, Spitsbergen JM, Kim KB, Tuttle JB, Steers WD: Histological and neurotrophic changes triggered by varying models of bladder inflammation. J Urol 2001, 166(3):1111-1118.

82. Bjorling DE, Wang ZY, Boldon $K$, Bushman W: Bacterial cystitis is accompanied by increased peripheral thermal sensitivity in mice. J Urol 2008, 179(2):759-763.

83. Guerios SD, Wang ZY, Boldon K, Bushman W, Bjorling DE: Blockade of NGF and trk receptors inhibits increased peripheral mechanical sensitivity accompanying cystitis in rats. Am J Physiol Regul Integr Comp Physiol 2008, 295(1):R111-R122.

84. DeBerry J, Randich A, Shaffer AD, Robbins MT, Ness TJ: Neonatal bladder inflammation produces functional changes and alters neuropeptide content in bladders of adult female rats. J Pain 2010, 11(3):247-255.

85. Randich A, Uzzell T, DeBerry JJ, Ness TJ: Neonatal urinary bladder inflammation produces adult bladder hypersensitivity. J Pain 2006, 7(7):469-479.

86. Robinson CJ, Stringer SE: The splice variants of vascular endothelial growth factor (VEGF) and their receptors. J Cell Sci 2001, 114(Pt 5):853-865.

87. Eichmann A, Makinen T, Alitalo K: Neural guidance molecules regulate vascular remodeling and vessel navigation. Genes Dev 2005, 19(9):1013-1021.

88. Tran J, Master Z, Yu JL, Rak J, Dumont DJ, Kerbel RS: A role for survivin in chemoresistance of endothelial cells mediated by VEGF. Proc Natl Acad Sci U S A 2002, 99(7):4349-4354.

89. Segarra M, Ohnuki H, Maric D, Salvucci O, Hou X, Kumar A, Li X, Tosato G: Semaphorin $6 \mathrm{~A}$ regulates angiogenesis by modulating VEGF signaling. Blood 2012, 120(19):4104-4115.

90. Yang S, Wu X, Luo C, Pan C, Pu J: Expression and clinical significance of hepaCAM and VEGF in urothelial carcinoma. World J Urol 2010, 28(4):473-478

91. Saban MR, Nguyen NB, Hammond TG, Saban R: Gene expression profiling of mouse bladder inflammatory responses to LPS, substance $P$, and antigen-stimulation. Am J Pathol 2002, 160(6):2095-2110.

92. Yu W, Hill WG: Defining protein expression in the urothelium: a problem of more than transitional interest. Am J Physiol Renal Physiol 2011, 301(5):F932-942.

93. Haarala M, Kiiholma P, Nurmi M, Uksila J, Alanen A: The role of Borrelia burgdorferi in interstitial cystitis. European urology 2000, 37(4):395-399.

94. Charrua A, Cruz CD, Narayanan S, Gharat L, Gullapalli S, Cruz F, Avelino A: GRC-6211, a new oral specific TRPV1 antagonist, decreases bladder overactivity and noxious bladder input in cystitis animal models. J Urol 2009, 181(1):379-386.

95. Finney-Hayward TK, Popa MO, Bahra P, Li S, Poll CT, Gosling M, Nicholson AG, Russell RE, Kon OM, Jarai G, Westwick J, Barnes PJ, Donnelly LE: Expression of transient receptor potential c6 channels in human lung macrophages. Am J Respir Cell Mol Biol 2010, 43(3):296-304.

96. Rudick CN, Chen MC, Mongiu AK, Klumpp DJ: Organ cross talk modulates pelvic pain. Am J Physiol Regul Integr Comp Physiol 2007, 293(3):R1191-1198.

doi:10.1186/1472-6793-12-15

Cite this article as: Malykhina et al:: VEGF induces sensory and motor peripheral plasticity, alters bladder function, and promotes visceral sensitivity. BMC Physiology 2012 12:15.

\section{Submit your next manuscript to BioMed Central and take full advantage of:}

- Convenient online submission

- Thorough peer review

- No space constraints or color figure charges

- Immediate publication on acceptance

- Inclusion in PubMed, CAS, Scopus and Google Scholar

- Research which is freely available for redistribution

Submit your manuscript at www.biomedcentral.com/submit
C Biomed Central 